\title{
Contribution of ocean, fossil fuel, land biosphere, and biomass burning carbon fluxes to seasonal and interannual variability in atmospheric $\mathrm{CO}_{2}$
}

\author{
Cynthia D. Nevison, ${ }^{1}$ Natalie M. Mahowald, ${ }^{1,2}$ Scott C. Doney ${ }^{3}$ Ivan D. Lima, ${ }^{3}$ \\ Guido R. van der Werf, ${ }^{4}$ James T. Randerson, ${ }^{5}$ David F. Baker, ${ }^{3}$ Prasad Kasibhatla, ${ }^{6}$ \\ and Galen A. McKinley ${ }^{7}$ \\ Received 12 January 2007; revised 1 June 2007; accepted 2 November 2007; published 12 February 2008.
}

[1] Seasonal and interannual variability in atmospheric carbon dioxide $\left(\mathrm{CO}_{2}\right)$ concentrations was simulated using fluxes from fossil fuel, ocean and terrestrial biogeochemical models, and a tracer transport model with time-varying winds. The atmospheric $\mathrm{CO}_{2}$ variability resulting from these surface fluxes was compared to observations from 89 GLOBALVIEW monitoring stations. At northern hemisphere stations, the model simulations captured most of the observed seasonal cycle in atmospheric $\mathrm{CO}_{2}$, with the land tracer accounting for the majority of the signal. The ocean tracer was 3-6 months out of phase with the observed cycle at these stations and had a seasonal amplitude only $\sim 10 \%$ on average of observed. Model and observed interannual $\mathrm{CO}_{2}$ growth anomalies were only moderately well correlated in the northern hemisphere $(\mathrm{R} \sim 0.4-0.8)$, and more poorly correlated in the southern hemisphere $(\mathrm{R}<0.6)$.

Land dominated the interannual variability (IAV) in the northern hemisphere, and biomass burning in particular accounted for much of the strong positive $\mathrm{CO}_{2}$ growth anomaly observed during the 1997-1998 El Niño event. The signals in atmospheric $\mathrm{CO}_{2}$ from the terrestrial biosphere extended throughout the southern hemisphere, but oceanic fluxes also exerted a strong influence there, accounting for roughly half of the IAV at many extratropical stations. However, the modeled ocean tracer was generally uncorrelated with observations in either hemisphere from 1979-2004, except during the weak El Niño/ post-Pinatubo period of the early 1990s. During that time, model results suggested that the ocean may have accounted for $20-25 \%$ of the observed slowdown in the atmospheric $\mathrm{CO}_{2}$ growth rate.

Citation: Nevison, C. D., N. M. Mahowald, S. C. Doney, I. D. Lima, G. R. van der Werf, J. T. Randerson, D. F. Baker, P. Kasibhatla, and G. A. McKinley (2008), Contribution of ocean, fossil fuel, land biosphere, and biomass burning carbon fluxes to seasonal and interannual variability in atmospheric $\mathrm{CO}_{2}, J$. Geophys. Res., 113, G01010, doi:10.1029/2007JG000408.

\section{Introduction}

[2] The increase in atmospheric $\mathrm{CO}_{2}$ from a preindustrial level of $280 \mathrm{ppm}$ to the 2006 level of over $380 \mathrm{ppm}$ has been well documented in ice core and firn data and by direct

\footnotetext{
${ }^{1}$ National Center for Atmospheric Research, Boulder, Colorado, USA.

${ }^{2}$ Now at Department of Earth and Atmospheric Sciences, Cornell University, Ithaca, New York, USA.

${ }^{3}$ Department of Marine Chemistry and Geochemistry, Woods Hole Oceanographic Institution, Woods Hole, Massachusetts, USA.

${ }^{4}$ Faculty of Earth and Life Sciences, Vrije Universiteit, Amsterdam, Netherlands.

${ }^{5}$ Earth System Science Department, University of California, Irvine, California, USA.

${ }^{6}$ Nicolas School of the Environment, Duke University, Durham, North Carolina, USA.

${ }^{7}$ Department of Atmospheric and Oceanic Sciences, University of Wisconsin, Madison, Wisconsin, USA.
}

Copyright 2008 by the American Geophysical Union. 0148-0227/08/2007JG000408\$09.00 atmospheric measurements beginning in the late 1950s [Keeling et al., 1989]. Anthropogenic fossil fuel combustion and cement manufacture drive most of the recent global atmospheric increase, but natural biogeochemical sources and sinks of $\mathrm{CO}_{2}$ control much of the variability observed in atmospheric $\mathrm{CO}_{2}$ data on seasonal and interannual timescales. The seasonal cycle in atmospheric $\mathrm{CO}_{2}$ is attributed mainly to a seasonal imbalance between terrestrial net primary production and heterotrophic respiration [Fung et al., 1983, 1987]. The large interannual variability (IAV) observed in the atmospheric $\mathrm{CO}_{2}$ growth rate is caused by year to year changes in net uptake of $\mathrm{CO}_{2}$ by land and ocean sinks, which have absorbed more than half on average of the total anthropogenic input (including $\mathrm{CO}_{2}$ released by deforestation, discussed below) over the last 50 years. The fossil fuel and cement input, in contrast, increases more or less steadily with time and cannot explain the observed IAV [Prentice et al., 2001]. 
[3] Deforestation and biomass burning provide an additional anthropogenic source of $\mathrm{CO}_{2}$ to the atmosphere. The deforestation source is currently estimated to be approximately $10-20 \%$ of the fossil and cement flux, although its magnitude and variability are much less precisely known [Houghton, 2003]. Furthermore, uptake and long-term storage of carbon in other parts of the terrestrial biosphere, e.g., from forest regrowth, tend to compensate for deforestation such that the terrestrial biosphere on average has been a small net sink of carbon over recent decades [Prentice et al., 2001]. Bottom-up estimates based on data extrapolations and process-based models can distinguish between deforestation loss and terrestrial uptake [Dargaville et al., 2002; Houghton, 2003]. Inverse methods, using atmospheric $\mathrm{CO}_{2}$ and complementary ${ }^{13} \mathrm{C}$ and $\mathrm{O}_{2} / \mathrm{N}_{2}$ data, provide top-down constraints on these models and data extrapolations, but can only resolve the net terrestrial flux [Keeling et al., 1996; Battle et al., 2000; Bender et al., 2005; Baker et al., 2006].

[4] The ocean carbon sink has been quantified by a variety of methodologies, including process-based ocean models, surface data extrapolations, subsurface data inventories and atmospheric and oceanic inversions. Some methods directly quantify the geochemical uptake of anthropogenic $\mathrm{CO}_{2}$ by the ocean [Gloor et al., 2003; Quay et al., 2003; Bender et al., 2005; Matsumoto and Gruber, 2005], while other methods measure the net global air-sea $\mathrm{CO}_{2}$ exchange [Takahashi et al., 2002; Baker et al., 2006]. These latter estimates must be corrected by a net outgassing of $\sim 0.6 \mathrm{Pg} \mathrm{C} / \mathrm{yr}$ from river export [Sarmiento and Sundquist, 1992] before they can be compared directly to the former results. Despite these complexities, most estimates of the anthropogenic ocean sink tend to converge around $\sim 2 \pm 1 \mathrm{Pg} \mathrm{C} / \mathrm{yr}$ for the 1990s [Orr et al., 2001; Prentice et al., 2001; Bender et al., 2005]. In addition, the methodologies capable of partitioning land and ocean carbon sinks generally agree that the ocean accounts for the majority of the overall uptake of anthropogenic $\mathrm{CO}_{2}$ but that most of the IAV in the atmospheric $\mathrm{CO}_{2}$ growth rate is controlled by the net terrestrial term [Keeling et al., 1996; Lee et al., 1998; Battle et al., 2000; Bousquet et al., 2000; Le Quéré et al., 2003; Baker et al., 2006].

[5] Although the literature tends to agree on the overall magnitude of the ocean sink and on its secondary importance relative to the net land sink in determining IAV in atmospheric $\mathrm{CO}_{2}$, substantial gaps in understanding remain. Atmospheric inverse methods based on atmospheric $\mathrm{CO}_{2}$, ${ }^{13} \mathrm{C}$ and $\mathrm{O}_{2} / \mathrm{N}_{2}$ suggest that oceanic IAV ranges from about 1 to $3 \mathrm{Pg} \mathrm{C} / \mathrm{yr}$ [Bender et al., 2005; Baker et al., 2006], whereas process-based ocean carbon models generally predict IAV of $<1 \mathrm{Pg} \mathrm{C/yr} \mathrm{[Le} \mathrm{Quéré} \mathrm{et} \mathrm{al.,} \mathrm{2000,} \mathrm{2003;} \mathrm{Obata}$ and Kitamura, 2003; McKinley et al., 2004a]. Oceanic measurements support IAV in the equatorial oceans of at most $0.8 \mathrm{Pg} \mathrm{C} / \mathrm{yr}$ [Feely et al., 2002], while observations in extratropical regions are too sparse to determine yearly changes in $\mathrm{CO}_{2}$ uptake.

[6] The seasonal cycle of the ocean $\mathrm{CO}_{2}$ flux is also not fully understood. In general, it is smaller than that of land due to the natural buffering of $\mathrm{CO}_{2}$ by ocean carbonate chemistry and to the competition between thermal solubility effects and biological/circulation-driven changes in dissolved inorganic carbon (DIC). Analysis of observed surface $\mathrm{pCO}_{2}$ suggests that biological and mixing effects dominate the $\mathrm{pCO}_{2}$ seasonal cycle at high latitudes, that there is little cycle at the equator, and that thermal effects dominate in the subtropical gyres [Takahashi et al., 2002]. In the high latitude North Pacific, McKinley et al. [2006] illustrated that many ocean models have difficulty resolving the observed $\mathrm{pCO}_{2}$ seasonal cycle because the net change in surface $\mathrm{pCO}_{2}$ is a small residual difference between the large and opposite thermal and DIC-driven terms.

[7] Previous tracer transport model simulations with carbon fluxes from terrestrial biosphere models have been reasonably successful in reproducing the observed seasonal cycle of atmospheric $\mathrm{CO}_{2}$, although the simulations have tended to underestimate the amplitude of the cycle at northern hemisphere observing stations [Randerson et al., 1997; Dargaville et al., 2002]. In some cases, the minimum in the model seasonal cycle was also too early by one to two months, possibly due to problems in the terrestrial models' freeze-thaw dynamics. The IAV in atmospheric $\mathrm{CO}_{2}$ due to terrestrial carbon fluxes has been investigated in these simulations, with much of the emphasis on the IAV in the amplitude of the seasonal cycle. Dargaville et al. [2002] also investigated the annual mean IAV in the net land sink and found a tendency of models to underestimate the observed IAV by more than $50 \%$. Recent work suggests that biomass burning, which is closely associated with El Niño-induced drought, may account for much of the IAV in the net terrestrial carbon sink [Langenfelds et al., 2002; Van der Werf et al., 2004].

[8] Many previous atmospheric transport simulations of total $\mathrm{CO}_{2}$, including land, ocean and fossil fuel surface fluxes, have been performed. These include forward simulations that have combined IAV in transport with cyclostationary (i.e., the same climatological seasonal cycle repeated each year) surface fluxes [Dargaville et al., 2000, 2003] or IAV in land (but not ocean) surface fluxes with cyclostationary transport [Dargaville et al., 2002]. Geels et al. [2004] simulated IAV in both terrestrial $\mathrm{CO}_{2}$ fluxes and atmospheric transport for nearly a decade but focused their analysis primarily on high frequency, synoptic variability.

[9] In addition to the forward simulations, many inverse models have been used to elucidate land and ocean surface $\mathrm{CO}_{2}$ flux variability [Gurney et al., 2003, 2004; Rödenbeck et al., 2003; Baker et al., 2006]. With the exception of Rödenbeck et al., these inversion studies have used cyclostationary atmospheric transport and large, homogenous regions as the basis for their ocean flux estimates. McKinley et al. [2004b] suggest that the use of small regions in Rödenbeck et al. reduces aggregation error and improves forward model/inversion agreement for the high latitude oceans.

[10] Here we present a comparison of observed seasonal and interannual variability in atmospheric $\mathrm{CO}_{2}$ to forward transport model simulations in which full IAV is included in both transport and surface fluxes. The latter are obtained from ocean and terrestrial biogeochemistry models and fossil fuel databases. Our goals are (1) to assess whether the current generation of ocean and land models can capture the observed seasonal and interannual variability and (2) determine the relative importance of land and ocean fluxes for seasonal and interannual variability. Neither of these questions has been fully addressed using the latest generations of models. We begin in the Methods section with a description of the atmospheric chemical transport model, 
Table 1. Summary of Tracers Used to Calculate Seasonal and Interannual Variability in Atmospheric $\mathrm{CO}_{2}$

\begin{tabular}{lcc}
\hline \multicolumn{1}{c}{ Tracer } & Period of Analysis for Seasonal Cycle & Period of Analysis for IAV \\
\hline MATCH Tracers & & \\
Fossil Fuel & $1997-2004$ & $1979-2004$ \\
Ocean & & $1979-2004$ \\
WHOI best case & $1997-2004$ & $1979-2004$ \\
WHOI cyclostationary & $1997-2004$ & N/A \\
Takahashi et al. [2002] & $1986-1997$ & $1986-1997$ \\
MIT & & \\
Land & $1997-2004$ & N/A \\
CASA Neutral Biosphere (NB) & $1997-2004$ & $1997-2004$ \\
GFED NEP & $1997-2004$ & $1997-2004$ \\
GFED Uncorrected Biomass Burning (BB) & $1997-2004$ & $1997-2004$ \\
GFED best-case BB, corrected based on CO inversion & & $1997-2004$ \\
Total CO & $1997-2004$ & $1997-2004$ \\
$\quad$ (1) Best case = best ocean + GFED (NEP+best BB) + fossil fuel & $1997-2004$ & N/A \\
(2) Takahashi ocean + GFED (NEP+best BB) + fossil fuel & $1997-2004$ & $1997-2004$ \\
(3) best ocean + CASA NB + fossil fuel & $1997-2004$ & $1997-2004$ \\
(4) best ocean + GFED (NEP+uncorrected BB) + fossil fuel & & $1979-2004$ \\
GLBALVIEW Observations & & $1997-2004$ \\
89 Stations (Table 2) & N/A & \\
33 Stations (Table 3) & & \\
\hline
\end{tabular}

ocean, land and fossil fuel fluxes, as well as the atmospheric $\mathrm{CO}_{2}$ observations and analytical methods used to evaluate model results. We present and discuss our results in section 3, which is partitioned into seasonal variability, latitudinal gradients, temporal IAV and spatial IAV. The impact of IAV in ocean fluxes on atmospheric $\mathrm{CO}_{2}$ is emphasized in section 4, since this topic in particular has not been studied in a comprehensive fashion in previous studies. Section 4.1 examines IAV associated with El Niño cycles, and section 4.2 presents a comparison of IAV in ocean model fluxes to those inferred by the Transcom 3 inversion. We conclude in section 5 with a summary of our main findings.

\section{Methods}

\subsection{MATCH Atmospheric Transport Model and NCEP Meteorology}

[11] The atmospheric chemical transport model used here is the Model of Atmospheric Transport and Chemistry (MATCH) [Rasch et al., 1997; Mahowald et al., 1997]. The current study uses T62 horizontal resolution (about $1.9^{\circ}$ latitude by longitude) with 28 vertical levels, and includes transport by large scale advection as well as subgrid scale mixing by dry and moist convection. MATCH has an explicit planetary boundary layer formulation and produces a relatively strong "seasonal rectifier" of $\mathrm{CO}_{2}$ concentrations, especially when driven with NCEP reanalysis data [Gurney et al., 2003]. MATCH was run with a time step of 20 minutes using archived 6 hourly winds for the years 1979-2004 from the National Center for Environmental Prediction (NCEP) reanalyses [Kalnay et al., 1996]. Reanalysis products provide the best available estimate of the historical state of the atmosphere, since they combine model and observations, although they may still contain substantial regional spatial biases and tend to underestimate high temporal and spatial wind speed variability. The surface $\mathrm{CO}_{2}$ fluxes described in section 2.2 were interpolated from their original resolution to the modeled resolution and used as surface flux boundary conditions in MATCH. Each flux type was tracked in the model as a separate tracer.

\subsection{Surface $\mathrm{CO}_{2}$ Fluxes}

\subsubsection{WHOI Ocean Model}

[12] The principal surface ocean $\mathrm{CO}_{2}$ fluxes used in this study were produced by combining an ocean general circulation model with a marine ecosystem model. The ecosystem model includes a nutrient-phytoplankton-zooplanktondetritus (NPZD) food web with multi-nutrient limitation $(\mathrm{N}, \mathrm{P}, \mathrm{Si}, \mathrm{Fe})$ and specific phytoplankton functional groups [Doney et al., 1996; Moore et al., 2002, 2004]. The ecosystem model is embedded into an ocean biogeochemistry module based on the OCMIP model [Doney et al., 2004]. The underlying physical circulation model is the Parallel Ocean Program (POP), which was run on a displaced pole grid with a longitude resolution of $3.6^{\circ}$ and a latitude resolution ranging from $0.6^{\circ}$ in the tropics to $2.8^{\circ}$ at midlatitudes. POP was forced with daily averaged NCEP reanalysis surface winds, atmospheric temperature and humidity, and satellite data products from 1979-2004 [Doney et al., 1998, 2007], consistent with the MATCH simulation. The MATCH results presented below are based on monthly mean ocean fluxes. Two different WHOI ocean $\mathrm{CO}_{2}$ fluxes were tested in MATCH (Table 1): (a) a best-case run, in which realistic IAV was included in all physical drivers, including wind, SST, solar radiation, heat flux, and iron dust deposition, (b) a cyclostationary run using the climatological average from 1979-2004 of the best-case run.

2.2.2. Takahashi Surface Ocean $\mathrm{CO}_{2}$ Flux Climatology

[13] For comparison to the WHOI ocean model, MATCH simulations were conducted from 1988-2004 with the airsea $\mathrm{CO}_{2}$ flux estimated from the global monthly climatology of underway $\triangle \mathrm{pCO}_{2}$ measurements [Takahashi et al., 2002] (http://www.ldeo.columbia.edu). The $\Delta \mathrm{pCO}_{2}$ maps were constructed by projecting 40 years of historical data, excluding El Niño years, onto a single virtual year (1995). Takahashi et al. estimated the surface $\mathrm{CO}_{2}$ flux from $\triangle \mathrm{pCO}_{2}$ using $10-\mathrm{m}$ mean wind speeds from 41 years of NCEP reanalysis and the Wanninkhof [1992] quadratic wind speed dependence for the sea-air $\mathrm{CO}_{2}$ gas transfer coefficient $k$. (Note: we used the corrected $\mathrm{CO}_{2}$ fluxes downloaded from the Columbia website, which used $10 \mathrm{~m}$ height 
Table 2. Eighty-Nine GLOBALVIEW Stations With $\mathrm{CO}_{2}$ Records Containing $\geq \sim 60 \%$ Real Data From 1997 to $2004^{\mathrm{a}}$

\begin{tabular}{|c|c|c|c|c|c|c|c|c|}
\hline Station & Code & Latitude & Longitude & Elevation & Rtot & Rlnd & Rnep & $\mathrm{Rbb}$ \\
\hline Alert & ALT & 82.5 & -62.5 & 210 & $0.74^{\mathrm{b}}$ & $0.72^{\mathrm{c}}$ & $0.64^{\mathrm{b}}$ & \\
\hline Amsterdam Island & AMS & -38.0 & 77.5 & 150 & & & & \\
\hline Ascension Island & $\mathrm{ASC}$ & -7.9 & -14.4 & 54 & & & & \\
\hline Assekrem Algeria & ASK & 23.2 & 5.4 & 2728 & & & & \\
\hline Azores & AZR & 38.8 & -27.1 & 30 & $0.63^{\mathrm{c}}$ & $0.67^{\mathrm{c}}$ & & \\
\hline Baltic Sea Poland & BAL & 55.5 & 16.7 & 7 & $0.66^{\mathrm{b}}$ & $0.58^{\mathrm{c}}$ & $0.61^{\mathrm{b}}$ & \\
\hline Baring Head NZ & BHD & -41.4 & 174.9 & 80 & & & & \\
\hline Bermuda West & BMW & 32.3 & -64.9 & 30 & & & & \\
\hline Bermuda East & BME & 32.3 & -64.7 & 30 & & & & \\
\hline Barrow Alaska & BRW & 71.3 & -156.6 & 11 & & $0.64^{\mathrm{c}}$ & & \\
\hline Black Sea Romania & $\mathrm{BSC}$ & 44.2 & 28.7 & 3 & & & & \\
\hline Carr CO & $\mathrm{C} 3 \mathrm{~K}$ & 40.9 & -104.8 & 3000 & & & & \\
\hline Carr CO & $\mathrm{C} 4 \mathrm{~K}$ & 40.9 & -104.8 & 4000 & & & & \\
\hline Carr CO & $\mathrm{C} 5 \mathrm{~K}$ & 40.9 & -104.8 & 5000 & & & & \\
\hline Carr CO & C6K & 40.9 & -104.8 & 6000 & & & & \\
\hline Carr CO & $\mathrm{C} 7 \mathrm{~K}$ & 40.9 & -104.8 & 7000 & & & & \\
\hline Carr CO & $\mathrm{C} 8 \mathrm{~K}$ & 40.9 & -104.8 & 8000 & & & & \\
\hline Cold Bay Alaska & CBA & 55.2 & -162.7 & 25 & & & & \\
\hline Cape Ferguson Aust. & CFA & -19.3 & 147.1 & 2 & & & & \\
\hline Cape Grim Tasmania & CGO & -40.7 & 144.7 & 94 & & & & \\
\hline Christmas Island & CHR & 1.7 & -157.2 & 3 & & & & \\
\hline Mt. Cimone Italy & $\mathrm{CMN}$ & 44.2 & 10.7 & 2165 & $0.66^{\mathrm{c}}$ & & & \\
\hline Cape Ochi-Ichi Japan & $\mathrm{COI}$ & 43.2 & 145.5 & 100 & $0.68^{\mathrm{b}}$ & $0.59^{\mathrm{c}}$ & & \\
\hline Cape Pt. South Africa & CPT & -34.4 & 18.5 & 230 & & & & \\
\hline Cape Rama India & CRI & 15.1 & 73.8 & 60 & & & & \\
\hline Crozet Island & CRZ & -46.5 & 51.9 & 120 & & & & \\
\hline Easter Island & EIC & -29.2 & -109.4 & 50 & & & & \\
\hline Estevan Pt B.C. & ESP & 49.4 & -126.6 & 39 & & & & \\
\hline Fraserdale Ontario & FRD & 49.9 & -81.6 & 210 & $0.51^{\mathrm{b}}$ & $0.51^{\mathrm{b}}$ & & \\
\hline Guam & GMI & 13.4 & 144.8 & 2 & & & & \\
\hline Hateruma Isl. Japan & HAT & 24.1 & 123.8 & 47 & $0.80^{\mathrm{b}}$ & & & \\
\hline Halley Bay Antarctica & HBA & -75.7 & -25.5 & 10 & & & & \\
\hline Hungary & HUN & 47.0 & 16.7 & 300 & $0.44^{\mathrm{c}}$ & & & \\
\hline Storhofdi Iceland & ICE & 63.3 & -20.2 & 100 & & & & \\
\hline Canary Islands & IZO & 28.3 & -16.5 & 2360 & & & & \\
\hline Jubany Antarctica & JBN & -62.2 & -58.8 & 15 & & & & \\
\hline Key Biscayne FL & KEY & 25.7 & -80.2 & 3 & & & & \\
\hline Kumukahi HA & KUM & 19.5 & -154.8 & 3 & & & & \\
\hline Kazakhstan Sary Tau & KZD & 44.5 & 75.6 & 412 & & & & \\
\hline Kazakhstan Plateau & KZM & 43.3 & 77.9 & 2519 & & & & \\
\hline Wisconsin Tower & LEF & 45.9 & -90.3 & 500 & & & & \\
\hline La Jolla CA & LJO & 32.9 & -117.3 & 16 & & & & \\
\hline Lampedusa Italy & LMP & 35.5 & 12.6 & 85 & $0.70^{\mathrm{b}}$ & $0.69^{\mathrm{c}}$ & $0.56^{\mathrm{c}}$ & \\
\hline Mawson Antarctica & MAA & -67.6 & 62.9 & 32 & & & & \\
\hline Mace Head Ireland & MHD & 53.3 & -9.9 & 25 & & & $0.44^{\mathrm{c}}$ & \\
\hline Sand Island Midway & MID & 28.2 & -177.4 & 4 & & & & \\
\hline Mauna Loa HA & MLO & 19.5 & -155.6 & 3397 & & & & \\
\hline Minamitorishima Japan & MNM & 24.3 & 154.0 & 8 & $0.69^{\mathrm{c}}$ & $0.67^{\mathrm{c}}$ & & \\
\hline Macquarie Island & MQA & -54.5 & 159.0 & 12 & & & & \\
\hline Niwot Ridge $\mathrm{CO}$ & NWR & 40.1 & -105.6 & 3475 & & & & \\
\hline Orleans France & O05 & 47.8 & 2.5 & 500 & & & & \\
\hline Orleans France & $\mathrm{O} 15$ & 47.8 & 2.5 & 1500 & & & & \\
\hline Orleans France & $\mathrm{O} 25$ & 47.8 & 2.5 & 2500 & & & & \\
\hline Orleans France & $\mathrm{O} 35$ & 47.8 & 2.5 & 3500 & & & & \\
\hline Pallas Finland & PAL & 68.0 & 24.1 & 560 & $0.77^{\mathrm{b}}$ & $0.69^{\mathrm{c}}$ & $0.72^{\mathrm{b}}$ & \\
\hline Pacific Ocean & N00 & 0.0 & -155.0 & 0 & & & & \\
\hline Pacific Ocean & N05 & 5.0 & -151.0 & 0 & & & & $0.84^{\mathrm{c}}$ \\
\hline Pacific Ocean & N10 & 10.0 & -149.0 & 0 & & & & $0.83^{\mathrm{c}}$ \\
\hline Pacific Ocean & N15 & 15.0 & -145.0 & 0 & $0.77^{\mathrm{c}}$ & $0.75^{\mathrm{c}}$ & & $0.83^{\mathrm{c}}$ \\
\hline Pacific Ocean & N20 & 20.0 & -141.0 & 0 & & & & $0.75^{\mathrm{c}}$ \\
\hline Pacific Ocean & N25 & 25.0 & -139.0 & 0 & & $0.74^{\mathrm{c}}$ & & $0.79^{\mathrm{c}}$ \\
\hline Pacific Ocean & N30 & 30.0 & -135.0 & 0 & & & & \\
\hline Pacific Ocean & S05 & -5.0 & -159.0 & 0 & & & & \\
\hline Pacific Ocean & $\mathrm{S} 10$ & -10.0 & -161.0 & 0 & & & & \\
\hline Pacific Ocean & S15 & -15.0 & -171.0 & 0 & & & & \\
\hline Pacific Ocean & S20 & -20.0 & -174.0 & 0 & & & & \\
\hline Pacific Ocean & $\mathrm{S} 25$ & -25.0 & -171.0 & 0 & & & & \\
\hline Plateau Rosa Italy & PRS & 45.9 & 7.7 & 3480 & & & & \\
\hline Palmer Antarctica & PSA & -64.9 & -64.0 & 10 & & & & \\
\hline Ragged Pt. Barbados & RPB & 13.2 & -59.4 & 3 & & & & \\
\hline Ryori Japan & RYO & 39.0 & 141.8 & 230 & $0.62^{\mathrm{b}}$ & & & \\
\hline Schauinsland Germany & $\mathrm{SCH}$ & 48.0 & 8.0 & 1205 & & & & \\
\hline Mahe Island Seychelles & SEY & -4.7 & 55.2 & 3 & & & & \\
\hline
\end{tabular}


Table 2. (continued)

\begin{tabular}{|c|c|c|c|c|c|c|c|c|}
\hline Station & Code & Latitude & Longitude & Elevation & Rtot & Rlnd & Rnep & $\mathrm{Rbb}$ \\
\hline Shemya Island AK & SHM & 52.7 & 174.1 & 40 & $0.74^{\mathrm{b}}$ & $0.71^{\mathrm{b}}$ & & $0.74^{\mathrm{c}}$ \\
\hline Shetland Isl. Scotland & SIS & 60.2 & -1.2 & 30 & & & $0.59^{\mathrm{c}}$ & \\
\hline Samoa & SMO & -14.3 & -170.6 & 42 & & & & \\
\hline South Pole & SPO & -90.0 & -24.8 & 2830 & & & & \\
\hline Atlantic Ocean Norway & STM & 66.0 & 2.0 & 7 & $0.80^{\mathrm{b}}$ & $0.67^{\mathrm{c}}$ & $0.64^{\mathrm{c}}$ & \\
\hline Summit Greenland & SUM & 72.6 & -38.5 & 3238 & $0.60^{\mathrm{c}}$ & & & \\
\hline Syowa Antarctica & SYO & -69.0 & 39.6 & 11 & & & & \\
\hline Tae-ahn Penin. Korea & TAP & 36.7 & 126.1 & 20 & & & & \\
\hline Tierra del Fuego & TDF & -54.9 & -68.5 & 20 & & & & \\
\hline Wendover Utah & UTA & 39.9 & -113.7 & 1320 & & & $0.45^{\mathrm{c}}$ & \\
\hline Ulaan Uul Mongolia & UUM & 44.5 & 111.1 & 914 & & & & \\
\hline Westerland North Sea & WES & 55.0 & 8.0 & 8 & $0.60^{\mathrm{b}}$ & $0.60^{\mathrm{c}}$ & $0.54^{\mathrm{c}}$ & \\
\hline Sede Boker Israel & WIS & 31.1 & 34.9 & 400 & $0.64^{\mathrm{c}}$ & $0.65^{\mathrm{c}}$ & & \\
\hline Qinghai Province PRC & WLG & 36.3 & 100.9 & 3810 & & & $0.61^{\mathrm{b}}$ & \\
\hline Yonagunijima Japan & YON & 24.5 & 123.0 & 30 & $0.74^{\mathrm{c}}$ & & & \\
\hline Zeppelin Norway & ZEP & 78.9 & 11.9 & 474 & $0.66^{\mathrm{c}}$ & $0.67^{\mathrm{b}}$ & $0.61^{\mathrm{c}}$ & \\
\hline
\end{tabular}

${ }^{\mathrm{a}}$ The coefficients (R) for total $\mathrm{CO}_{2}$, net GFED land, NEE, and BB tracers yielding statistically significant correlations with observations of IAV are listed.

${ }^{\mathrm{b}}$ Here $1 \%<\mathrm{p}<5 \%$.

${ }^{\mathrm{c}}$ Here $5 \%<\mathrm{p}<10 \%$.

wind speeds in the Wanninkhof formula.) Although only one climatological year of the Takahashi $\mathrm{CO}_{2}$ fluxes exists, the MATCH simulation included some interannual variability in this flux by including IAV in wind speeds. This was done by scaling the flux by the ratio of the monthly mean of the square of the NCEP wind speed in a given year by the climatological monthly mean of the square of the NCEP wind speed from 1988 to 2004. This scaling approach was based on the commonly assumed 2 nd order dependence on wind speed [Wanninkhof, 1992] although recent studies propose wind speed power dependences for $k$ ranging from below 1 [Krakauer et al., 2006] to 3 [Wanninkhof and McGillis, 1999].

Table 3. Thirty-Three GLOBALVIEW Stations With $\mathrm{CO}_{2}$ Records Containing $\geq \sim 60 \%$ Real Data From 1979 to $2004^{\mathrm{a}}$

\begin{tabular}{|c|c|c|c|c|c|c|}
\hline Station & Code & Latitude & Longitude & Elevation, $\mathrm{m}$ & Rff & Rocn \\
\hline Alert & ALT & 82.5 & -62.5 & 210 & & \\
\hline Amsterdam Island & AMS & -38.0 & 77.5 & 150 & & \\
\hline Ascension Island & $\mathrm{ASC}$ & -7.9 & -14.4 & 54 & & \\
\hline Azores & AZR & 38.8 & -27.1 & 30 & & \\
\hline Baring Head NZ & BHD & -41.4 & 174.9 & 80 & & \\
\hline Bermuda West & BMW & 32.3 & -64.9 & 30 & & \\
\hline Bermuda East & BME & 32.3 & -64.7 & 30 & & \\
\hline Barrow Alaska & BRW & 71.3 & -156.6 & 11 & $0.43^{\mathrm{b}}$ & \\
\hline Cold Bay Alaska & CBA & 55.2 & -162.7 & 25 & & $0.30^{\mathrm{c}}$ \\
\hline Cape Grim Tasmania & $\mathrm{CGO}$ & -40.7 & 144.7 & 94 & & \\
\hline Christmas Island & CHR & 1.7 & -157.2 & 3 & & \\
\hline Mt. Cimone Italy & $\mathrm{CMN}$ & 44.2 & 10.7 & 2165 & $0.30^{\mathrm{b}}$ & \\
\hline Guam & GMI & 13.4 & 144.8 & 2 & & \\
\hline Halley Bay Antarctica & HBA & -75.7 & -25.5 & 10 & & \\
\hline Canary Islands & IZO & 28.3 & -16.5 & 2360 & & \\
\hline Key Biscayne FL & KEY & 25.7 & -80.2 & 3 & & \\
\hline Kumukahi HA & KUM & 19.5 & -154.8 & 3 & & \\
\hline Mould Bay Canada & $\mathrm{MBC}$ & 76.3 & -119.3 & 58 & $0.42^{\mathrm{b}}$ & \\
\hline Sand Island Midway & MID & 28.2 & -177.4 & 4 & & \\
\hline Mauna Loa HA & MLO & 19.5 & -155.6 & 3397 & & \\
\hline Niwot Ridge CO & NWR & 40.1 & -105.6 & 3475 & & \\
\hline Palmer Antarctica & PSA & -64.9 & -64.0 & 10 & & \\
\hline Ragged Pt. Barbados & $\mathrm{RPB}$ & 13.2 & -59.4 & 3 & & \\
\hline Ryori Japan & RYO & 39.0 & 141.8 & 230 & & \\
\hline Sable Island Nova Scot. & SBL & 43.9 & -60.0 & 5 & & \\
\hline Schauinsland Germany & $\mathrm{SCH}$ & 48.0 & 8.0 & 1205 & & \\
\hline Mahe Island Seychelles & SEY & -4.7 & 55.2 & 3 & & \\
\hline Shemya Island AK & SHM & 52.7 & 174.1 & 40 & & \\
\hline Samoa & SMO & -14.3 & -170.6 & 42 & $0.36^{\mathrm{c}}$ & $0.47^{\mathrm{b}}$ \\
\hline South Pole & SPO & -90.0 & -24.8 & 2830 & & \\
\hline Atlantic Ocean Norway & STM & 66.0 & 2.0 & 7 & & \\
\hline Syowa Antarctica & SYO & -69.0 & 39.6 & 11 & & \\
\hline Westerland North Sea & WES & 55.0 & 8.0 & 8 & $0.29^{\mathrm{c}}$ & \\
\hline
\end{tabular}

${ }^{a}$ The coefficients (R) for fossil fuel and oceanic $\mathrm{CO}_{2}$ tracers yielding statistically significant correlations with observations of IAV are listed.

${ }^{\mathrm{b}}$ Here $1 \%<\mathrm{p}<5 \%$.

${ }^{\mathrm{c}}$ Here $5 \%<\mathrm{p}<10 \%$. 


\subsubsection{MIT Ocean Carbon Model}

[14] For some sensitivity studies, results are shown from MATCH simulations using $\mathrm{CO}_{2}$ fluxes for 1986-1997 from the MIT ocean carbon model [McKinley et al., 2004a]. In comparison to the WHOI ocean model, the MIT model uses a higher resolution general circulation model $\left(0.3^{\circ}\right.$ to $1^{\circ} \times$ $1^{\circ}$ ) and a simple export production parameterization to represent carbon biogeochemistry.

\subsubsection{Land Biosphere Fluxes}

[15] Two versions of the CASA land biosphere model were used for terrestrial $\mathrm{CO}_{2}$ fluxes. The first was a cyclostationary "neutral biosphere" (NB) version, run in MATCH from 1979-2004, in which net ecosystem production [NEP; the balance between heterotrophic respiration $\left(\mathrm{R}_{\mathrm{h}}\right)$ and net primary production (NPP)] was assumed to be zero at each grid cell [Randerson et al., 1997]. The NB fluxes were 3 hourly and thus included both the diurnal and the seasonal cycle following the approach described by Olsen and Randerson [2004]. The second was the Global Fire Emissions Database (GFED v2) version in which satellite-based estimates of burned area from 1997-2004 [Giglio et al., 2006] were combined with CASA biomedependent parameters, including fuel types and fuel density, to estimate monthly variability in biomass burning emissions at a $1^{\circ} \times 1^{\circ}$ spatial resolution [Randerson et al., 2005; Van der Werf et al., 2006]. The GFED v2 model provides separate fluxes for NPP, $\mathrm{R}_{\mathrm{h}}$, and biomass burning (BB), each of which was simulated as a separate tracer in MATCH. GFED component fluxes vary in magnitude from month to month and year to year, with the sum of all fluxes (the sum of NEP and BB) constrained to be approximately zero over the 8 year (1997-2004) period based on the model spin up procedure described by Van der Werf et al. [2006]. An additional best-case BB flux was estimated using regionally scaled GFED biomass burning emissions, in which scaling factors for 14 basis regions were derived by an inverse approach based on zonal-mean anomalies in MOPITT column CO concentrations during the 2002-2005 time period (P. Kasibhatla et al., manuscript in preparation, 2008).

2.2.5. Fossil Fuel and Cement Manufacture Emissions

[16] Temporally and spatially resolved maps of fossil fuel plus cement $\mathrm{CO}_{2}$ emissions were constructed by combining 1970, 1980, 1990 and $19951^{\circ} \times 1^{\circ}$ maps [Andres et al., 1996; Brenkert, 1998] with annually resolved totals from 10 global regions [Marland et al., 2003]. A mask for each of the regions was projected onto the $1^{\circ} \times 1^{\circ}$ maps and the annual totals for each region were interpolated both spatially and temporally between decades. The 1995 spatial distribution was assumed for all years after 1995. Emissions were assumed to increase linearly over the calendar year with no attempt to represent seasonality, although recent work suggests that seasonality in fossil fuel fluxes could influence the results of atmospheric inversions [Gurney et al., 2005].

\subsection{GLOBALVIEW Atmospheric $\mathrm{CO}_{2}$ Data}

[17] We evaluated the MATCH simulations using observed atmospheric $\mathrm{CO}_{2}$ concentration data from GLOBAL$V I E W-\mathrm{CO}_{2}$ [2006]. GLOBALVIEW is a data product in which flask and continuous $\mathrm{CO}_{2}$ observations at a global network of monitoring stations are quality controlled and fitted to give 48 pseudo-weekly synchronous $\mathrm{CO}_{2}$ values per year. An extrapolation procedure is used to fill gaps in the observation records [Masarie and Tans, 1995], with statistics provided on whether real or filled observations are used. We selected sites at which real observations were available at least $\sim 60 \%$ of the time. This selection criterion was met at 89 stations across a broad spatial range for 1997-2004 and for 33 stations across 1979-2004 (see Tables 2 and 3 for a list of the stations used). We also experimented with a stricter selection criterion of $80 \%$ or better real data, but this generally had little effect on our overall results (see Taylor Diagrams described below). To compare model results and observations, the 48 pseudoweekly $\mathrm{CO}_{2}$ data were averaged into 12 monthly means. Monthly mean MATCH results were then sampled at the latitude, longitude and pressure of the $1.9^{\circ} \times 1.9^{\circ} \times 28$ level model that corresponded most closely to the coordinates of the GLOBALVIEW station. In the case of coastal observation sites that are only sampled when winds come off the sea, we followed the Transcom protocol of sampling MATCH at the neighboring ocean grid cell displaced toward the preferential wind direction [Gurney et al., 2000].

\subsection{Analysis Methods}

\subsubsection{Seasonal Cycles}

[18] Mean seasonal cycles were calculated by fitting the 1997-2004 monthly means for each model $\mathrm{CO}_{2}$ tracer and GLOBALVIEW time series (see Table 1) to a polynomial + harmonic function [Thoning et al., 1989].

$$
\begin{aligned}
F(t)= & a_{0}+a_{1} t+a_{2} t^{2}+a_{3} t^{3}+a_{4} \sin (2 \pi t) \\
& +a_{5} \cos (2 \pi t)+a_{6} \sin (4 \pi t)+a_{7} \cos (4 \pi t)
\end{aligned}
$$

The optimal fit was determined by least squares regression in a recursive algorithm in which data points falling more than 2 standard deviations outside the fit were rejected and the remaining points refit to equation 1 until all points were within $2 \sigma$ of the fit. The last 4 terms of $F(t)$, i.e., the harmonic component, were used to identify the mean seasonal cycle.

\subsubsection{Interannual Variability}

[19] Atmospheric growth rate anomalies were calculated for MATCH tracers and GLOBALVIEW observations, as summarized in Table 1. Interannual variability in the atmospheric growth rate of $\mathrm{CO}_{2}$ was calculated by removing the seasonal cycle from the monthly mean GLOBALVIEW and model time series with a 12-month running average, and calculating the slope of the smoothed time series as a central difference. The absolute slopes were converted to atmospheric growth rate anomalies by either removing the mean slope (for time series with no obvious trend in the slope) or, in the case of fossil fuel, by removing an optimal linear fit determined by recursive least squares regression. The linear fit removal was necessary for the fossil fuel tracer because its slope was clearly increasing with time. Removing the mean or linear fit facilitated the comparison of tracers with different secular trends. For example, the ocean was a net sink of $\mathrm{CO}_{2}$ and thus the MATCH ocean tracer decreased over time, while fossil and hence total $\mathrm{CO}_{2}$ increased.

\subsubsection{Taylor Diagrams}

[20] Taylor diagrams are a convenient way to quantify and evaluate multiple aspects of model performance in a 
single polar coordinate plot [Taylor, 2001]. Taylor diagrams are used here to evaluate the model's ability to simulate the observed seasonal cycle or IAV. Each symbol on the Taylor diagrams represents a different GLOBALVIEW monitoring station. A separate diagram is shown for each MATCH tracer. The angle $\theta$ from the $\mathrm{x}$-axis in the polar plot is the arccosine of the correlation coefficient $\mathrm{R}$ between the model and observed time series, which reflects the agreement in shape and phasing of the two time series. A perfect phase correlation $(\mathrm{R}=1)$ would lie at $\theta=0$. The value on the radial axis is the ratio of standard deviations: $\sigma_{\text {model }} / \sigma_{\text {obs }}$. It represents the match between the amplitude of the model and observed seasonal cycle or IAV. If the model amplitude agrees perfectly with observations, the ratio is 1 . If the model amplitude is too large, the ratio will be $>1$, etc. The comparison of MATCH "total" results and observations can be viewed directly as an "evaluation" of the model, while the comparison of component fluxes (e.g., ocean, biomass burning, fossil fuel) to observations should be viewed rather as an effort to quantify their contribution to observed variability, since any given component flux on its own is not necessarily expected to reproduce observations.

[21] The statistical significance of the $\sigma_{\text {model }} / \sigma_{\text {obs }}$ ratios was assessed using an F-test of the hypothesis that $\sigma_{\text {model }}^{2}=$ $\sigma_{\text {obs }}^{2}$ (see Box 8.1 of Sokal and Rohlf [1981]). The statistical significance of the correlation coefficients was assessed by testing the hypothesis that true $\mathrm{R}=0$, which involves comparing the calculated $\mathrm{R}$ values to critical $\mathrm{R}$ values determined from a t-table (see Box 15.3 of Sokal and Rohlf [1981]). Both tests are a function of significance level and degrees of freedom $\nu(\nu=\mathrm{N}-1$ for the F-test and N-2 for the t-table). The seasonal cycle statistics calculated here are based in all cases on $\mathrm{N}=12$ data points, i.e., the mean monthly seasonal cycle from 1997-2004. The statistics for interannual variability have a more variable $\mathrm{N}$ due to the autocorrelation, which varied by station and tracer, that is introduced in part by the 12-month running mean used to deseasonalize the model and observed time series. To account for autocorrelation in each time series, we used an effective $\mathrm{N}\left(\mathrm{N}_{\text {eff }}=\right.$ $\mathrm{N} / \kappa$ ) to calculate $\nu$, where $\kappa$ is the integrated area of the autocorrelation vs. lag curve centered around 0 lag for which the autocorrelation coefficient $\rho>0.1$ [Carlin and Louis, 2000, p. 171]. For land and total $\mathrm{CO}_{2}$ calculations, which were based on monthly 1997-2004 time series (i.e., $\mathrm{N}=96$ minus 6 months at the beginning and end associated with the 12-month running average), typical values of $\mathrm{N}_{\text {eff }}$ were $\sim 6$ for $\mathrm{BB}, \sim 11$ for observed $\mathrm{CO}_{2}$, and $\sim 14$ for NEP. The low values of $\mathrm{N}_{\text {eff }}$ for $\mathrm{BB}$ reflect the high autocorrelation in the biomass burning time series. In all cases, the smaller of the observed and model $\mathrm{N}_{\text {eff }}$ was used to estimate $\nu$.

\subsubsection{RMS Variability}

[22] Latitude-longitude maps of Root Mean Square (RMS) variability were used to evaluate the spatial distribution of model variability. Such plots are nonspecific with respect to the timing of variability. Seasonal RMS variability was calculated as the RMS of the differences between model climatological monthly means and the climatological annual mean. For IAV, the RMS is computed as the RMS of the differences between each month and the corresponding month from the climatological seasonal cycle. RMS calculations were performed separately for land, ocean, fossil fuel and total (i.e., the sum of land, ocean and fossil components) $\mathrm{CO}_{2}$ tracers. The portional contribution of each tracer to RMS variability was calculated by dividing the component RMS by the total RMS. The sum of all components was often greater than 1 in cases of cancellation of signals among individual components.

\section{Results and Discussion}

\subsection{Seasonal Cycles}

[23] To demonstrate the characteristics of the modeled $\mathrm{CO}_{2}$ concentrations, we focus on 6 GLOBALVIEW stations, and then discuss the behavior at all 89 stations meeting the $60 \%$ real data criterion from 1997-2004. The MATCH simulations are generally able to capture the seasonal cycle in the Northern Hemisphere, but have more trouble close to the equator and in the Southern Hemisphere (Figure 1). The model results at Mauna Loa (MLO), Lampedusa, Italy (LMP), and Ocean Station, Norway (STM) confirm the general understanding that the land biosphere dominates the seasonality in atmospheric $\mathrm{CO}_{2}$ in the northern hemisphere. In the southern hemisphere, the contribution of other component fluxes to the total seasonal cycle is more substantial. At Samoa in the southern tropics, land and ocean components combine to create a double maximum seasonal cycle, similar to the observed cycle. At Cape Grim (CGO) and Palmer Station (PSA) in the mid to high latitude Southern Hemisphere, land and ocean tracers are in phase and of comparable magnitude. Either component tracer alone matches reasonably well to the observed seasonal cycle, but when ocean and land are added together, the amplitude of the resulting total $\mathrm{CO}_{2}$ tracer exceeds that of the observed cycle by a factor of 2 at PSA and 3 at CGO. According to the F-test, $\sigma_{\text {model }} / \sigma_{\text {obs }}$ ratios of $>1.9$ or $<0.55$ indicate statistically significant differences between model and observations at the $5 \%$ level. Fossil fuel generally has a small seasonal cycle and contributes little to the overall seasonal amplitude in either hemisphere, although its importance could be underestimated due to the lack of seasonality in the prescribed fossil surface flux.

[24] The cyclostationary neutral biosphere (NB) land $\mathrm{CO}_{2}$ tracer is similar to the GFED tracer at most stations, although the two tracers differ at Samoa and Cape Grim, mainly as a result of the biomass burning component of GFED. For the ocean carbon tracers, the WHOI best-case model ocean seasonal cycle is virtually identical to the cyclostationary run (latter not shown in Figure 1). In contrast, substantial differences in phasing occur between the Takahashi and WHOI tracers, especially in the mid to high latitude Southern Ocean.

[25] To show results from all 89 stations in a compact fashion, we use Taylor diagrams (introduced in the methodology section). In the Northern Hemisphere, where the land biosphere dominates the seasonal cycle, the shape and phasing of model and observations is in excellent agreement, regardless of whether the GFED or NB land tracer is used (Figure 2). At almost all northern stations, the correlation coefficient $\mathrm{R}$ between model and observations is $>0.7$, which is statistically significant at the $1 \%$ confidence level. However, the model tends to underestimate the amplitude of the Northern Hemisphere cycle by an average 

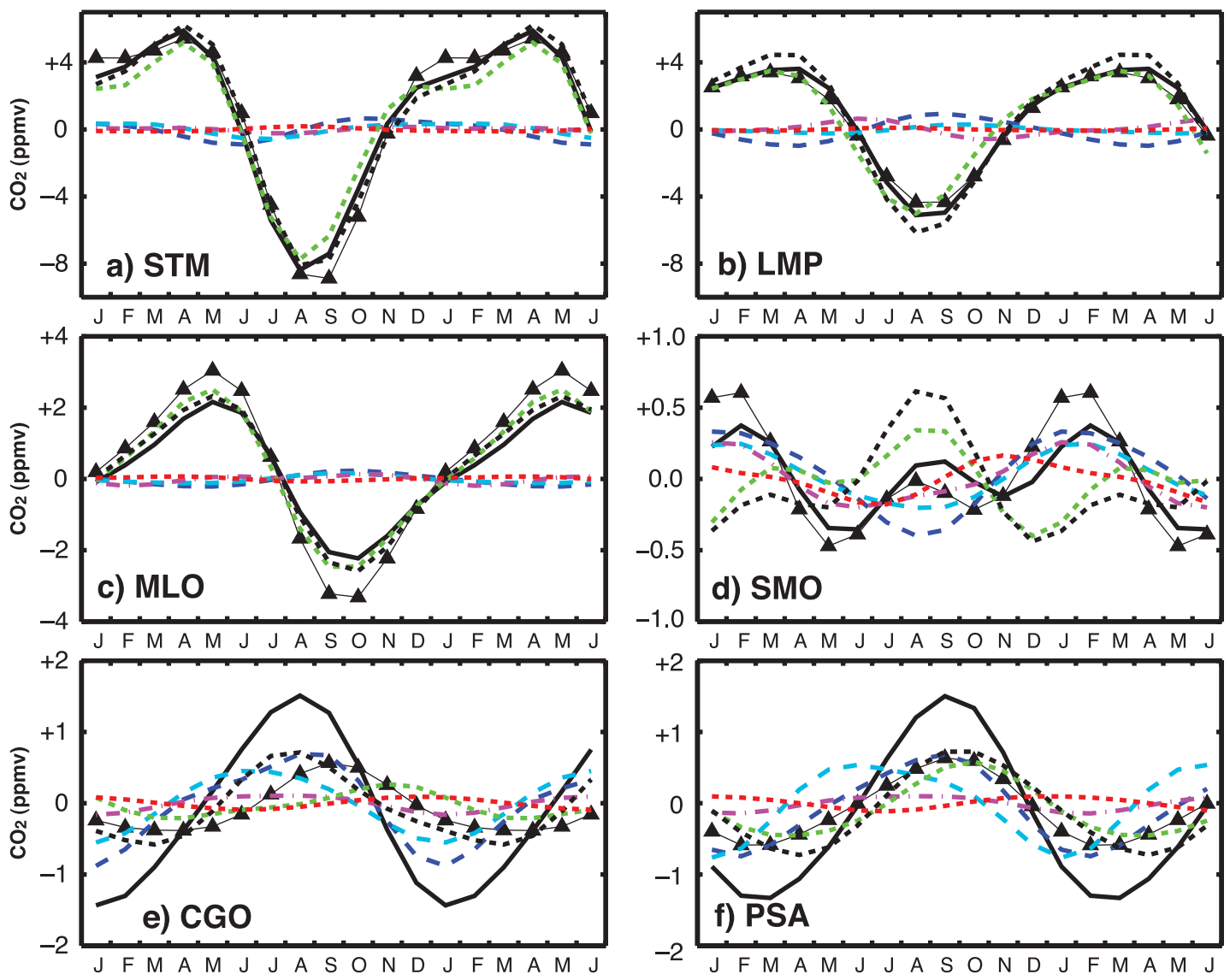

Figure 1. Seasonal cycles of atmospheric $\mathrm{CO}_{2}$ at six selected stations determined from mean harmonic fit to 1997-2004 time series. Thin black line with triangles is GLOBALVIEW observed cycle. Blue dashed line is WHOI best-case ocean, cyan dashed line is Takahashi ocean. Black dotted line is GFED land, green dotted line is neutral biosphere, red dotted line is the best-case biomass burning component of GFED. Magenta dot-dash line is fossil fuel. Solid heavy black line is best-case total $\mathrm{CO}_{2}$ (as defined in Table 1). (a) Ocean Station, Norway (STM), (b) Lampedusa, Italy (LMP, (c) Mauna Loa, Hawaii (MLO), (d) Samoa (SMO), (e) Cape Grim, Tasmania (CGO), and (f) Palmer Station, Antarctica (PSA).

of $\sim 20 \%$ and up to $50 \%$ at some stations. A similar tendency to underestimate the observed amplitude was found by Dargaville et al. [2002]. Strictly speaking, amplitude differences of $20 \%$ (as inferred from $\sigma_{\text {model }} / \sigma_{\text {obs }}$ ratios) are not statistically significant, according to the F-test describe above.

[26] The poorest agreement between model and observations occurs at several stations in the $\sim 33^{\circ} \mathrm{S}-45^{\circ} \mathrm{S}$ latitude belt (CGO, BHD, CPT, AMS), where the relative amplitude of the seasonal cycle $\left(\sigma_{\text {model }} / \sigma_{\text {obs }}\right)$ is 3 or more. A sensitivity study with only Northern Hemisphere land fluxes indicated that local land and biomass burning sources in Australia and South Africa are responsible for the large model amplitudes. The discrepancies between model and observations could be a sampling issue, since some of these stations only record samples when the wind comes off the sea, despite our attempts to address this issue by sampling the model at the nearest windward ocean grid as per Gurney et al. [2000].

[27] South of $45^{\circ} \mathrm{S}$, agreement between model total $\mathrm{CO}_{2}$ and observations improves to some extent. Model and observations are relatively well correlated $(\mathrm{R} \sim 0.8$ to 0.95), but the model amplitude is too large by a factor of
1.5 to nearly 3 . The GFED land and WHOI ocean tracers are generally in phase both with each other and with observations. The amplitude of either alone tends to match observations, but the combination of land and ocean overestimates the observed amplitude. A sensitivity study indicated that most of the land contribution at these latitudes comes from the northern hemisphere, consistent with past work [Randerson et al., 1997]. The agreement of total $\mathrm{CO}_{2}$ computed with the Takahashi ocean tracer arguably agrees better with observations than total $\mathrm{CO}_{2}$ computed with the WHOI ocean tracer, since the former only overestimates the observed amplitude at extratropical southern hemisphere stations by a factor of $\sim 2$ rather than $2.5-3$ for the latter; but this result could be caused by compensating errors in the land tracer.

[28] The tendency of models to overestimate the amplitude of total $\mathrm{CO}_{2}$ at extratropical southern stations has been noted in previous comparisons at the South Pole station [Randerson et al., 1997; Dargaville et al., 2002]. However, some previous studies used earlier versions of the WHOI ocean model or Takahashi et al. [2002] climatology, which produced an oceanic seasonal cycle of smaller amplitude, such that the resulting land-dominated $\mathrm{CO}_{2}$ cycle agreed 

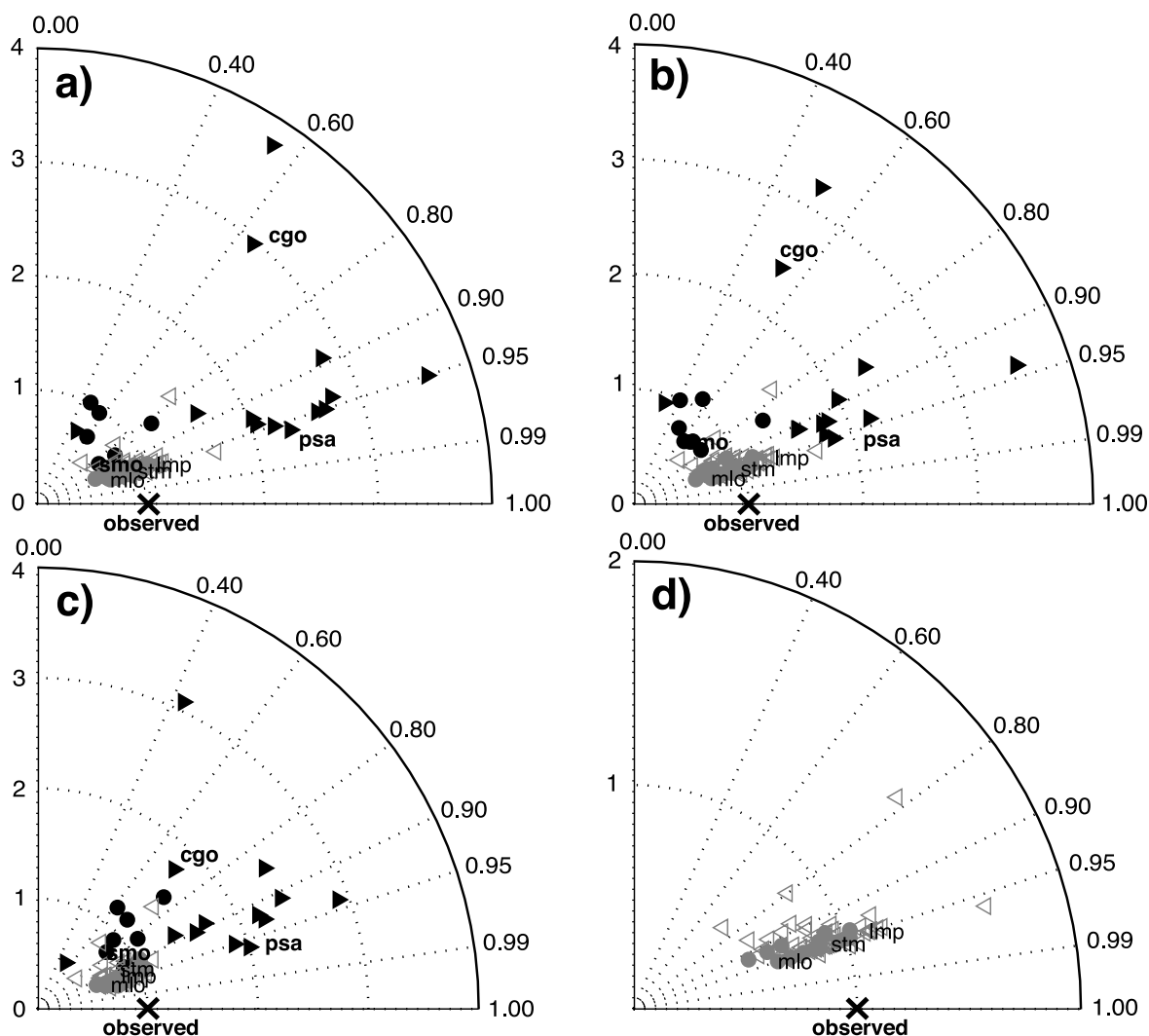

Figure 2. Taylor diagrams comparing the model seasonal cycle in total $\mathrm{CO}_{2}$ to GLOBALVIEW observations at 89 stations (see Table 2). Grey open left-facing triangles are extratropical $\left(>25^{\circ} \mathrm{N}\right)$ northern hemisphere stations, grey solid circles are tropical northern hemisphere stations, solid black circles are tropical southern hemisphere stations, and solid black right-facing triangles are extratropical $\left(<-25^{\circ} \mathrm{S}\right)$ southern hemisphere stations. The six stations featured in Figure 1 are explicitly labeled with their three-letter GLOBALVIEW code to help illustrate how the Taylor diagram quantifies the match between model and observations in both phasing, shape, and amplitude (also see section 2.4.3 in text). Perfect agreement with observations at $\theta=0$, and $\sigma_{\text {model }} / \sigma_{\text {obs }}=1$ is marked with an X. (a) Best-case total $\mathrm{CO}_{2}$ from Table 1, (b) Takahashi ocean + GFED land + fossil fuel, (c) WHOI best-case ocean + NB land + fossil fuel, and (d) as in Figure 2a except only northern hemisphere stations are shown. Note: in Figures $2 \mathrm{a}-2 \mathrm{c}$, Bearing Head, New Zealand, is a large outlier $\left(\sigma_{\text {model }} / \sigma_{\mathrm{obs}} \sim 6-8\right)$ and is not shown.

better with observations at southern hemisphere stations [Dargaville et al., 2002; Gurney et al., 2004]. Two possible explanations for the model tendency to overestimate the amplitude of the seasonal cycle in the Southern Hemisphere are (1) interhemispheric transport of the northern hemisphere land signal is too strong or (2) the seasonal cycle of the Southern Ocean $\mathrm{CO}_{2}$ flux is wrong in phasing and/or amplitude. The first explanation seems inconsistent with the model's general ability to capture the observed latitudinal gradient in $\mathrm{CO}_{2}$ (discussed below).

[29] An attempt to characterize the ${ }^{13} \mathrm{C}$ signature of the seasonal cycle at a range of southern stations based on the intercept of Keeling plots of ${ }^{13} \mathrm{CO}_{2}$ vs. $1 / \mathrm{CO}_{2}$ [Keeling, 1961; Randerson et al., 2002] was inconclusive as to the source of the signal. The plots yielded intercepts of -18 to -20 per mil, somewhere between a pure terrestrial C3 signal of $\sim-25$ per mil and a pure ocean signal of $\sim-10$ per mil, yet still implying a strong terrestrial component. A more comprehensive analysis of the ${ }^{13} \mathrm{CO}_{2}$ data would have to consider seasonal variability in the isotopic disequi- librium fluxes associated with the gross terrestrial and oceanic fluxes. It is possible that satellite column measurements of the amplitude of the $\mathrm{CO}_{2}$ seasonal cycle [Olsen and Randerson, 2004; Crisp et al., 2004], when compared to the seasonal cycle measured at surface stations, may help resolve the question of the land vs. ocean contribution. Our calculations suggest that the amplitude of the land tracer cycle in the extratropical southern hemisphere is nearly as large in the column as at the surface. In contrast, the column amplitude of the ocean tracer cycle is only $\sim 20 \%$ of the surface amplitude.

[30] The Taylor diagrams of individual $\mathrm{CO}_{2}$ tracers vs. observations in Figure 3 are presented in an effort to quantify the contributions of land, ocean and biomass burning to the observed seasonal cycle. In the Northern Hemisphere, both the WHOI model and Takahashi et al. [2002] climatological ocean seasonal cycles are small, with amplitudes typically $\sim 10 \pm 10 \%$ the magnitude of observed. The ocean cycles tend to be anticorrelated to observations, i.e., out of phase, suggesting a slightly larger amplitude for 


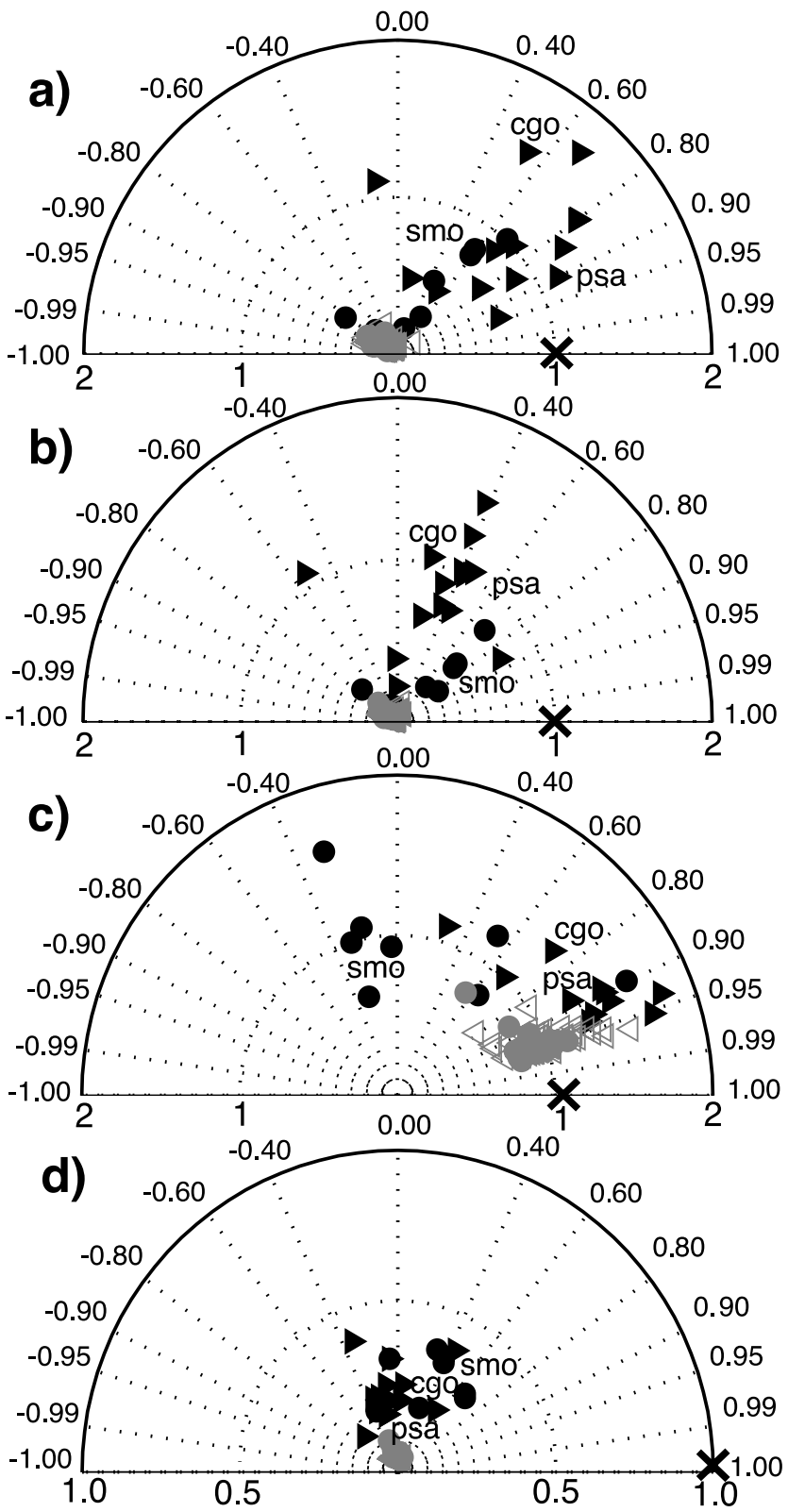

Figure 3. Taylor diagrams comparing the model seasonal cycle in component ocean, land, and biomass burning $\mathrm{CO}_{2}$ tracers to GLOBALVIEW observations at 89 stations. Symbols are as described in Figure 2. The diagrams now include two quadrants in order to display $\mathrm{R}$ values of $<0$, which reflect a phase lag of at least 3 months between model and observations. The three southern hemisphere stations (CGO, SMO, PSA) featured in Figure 1 are explicitly labeled with their three-letter GLOBALVIEW code. (a) WHOI bestcase ocean, (b) Takahashi ocean, (c) total GFED(= NEP + $\mathrm{BB}$ ), and (d) biomass burning (BB) component of GFED. In Figure 3c, stations $\mathrm{AMS}, \mathrm{BHD}$, and $\mathrm{CPT}$ are not shown because they are extreme outliers $\left(\sigma_{\bmod } / \sigma_{\text {obs }}>3\right)$.

the terrestrial biosphere seasonal cycle than would be estimated if the observed and land cycles are assumed to be exactly equivalent. In the Southern Hemisphere the WHOI ocean tracer can account for $100 \pm 80 \%$ of the amplitude of, and tends to be well correlated $(\mathrm{R} \sim 0.6$ to
$0.9)$ with, the observed seasonal cycle. The Takahashi et al. ocean tracer, in comparison, generally accounts for a similar portion of the observed amplitude but is less well correlated ( $\mathrm{R} \sim 0.4$ to 0.8 ) with observations. These results do not necessarily imply that the WHOI ocean tracer is more realistic than the Takahashi et al. tracer, since the model land tracer also contributes substantially to total $\mathrm{CO}_{2}$ at Southern Ocean stations.

[31] The GFED land tracer typically can account for all or nearly all the observed seasonal amplitude of $\mathrm{CO}_{2}$ at both northern and southern hemisphere stations. It is in phase with observations at most stations, with some strong exceptions in the southern tropics, where it is anticorrelated to observations. The biomass burning tracer makes a small contribution to the seasonal amplitude at tropical stations, and long range transport of this tracer can be considerable at high southern latitudes, where the total seasonal cycle due to other sources is small. In the northern extratropics, biomass burning events tend to be episodic and thus do not contribute substantially to the climatological seasonal cycle.

[32] While the correlation coefficient $\mathrm{R}$ can reflect agreement in either the shape or the phase of the agreement between model and observations, the $\mathrm{R}$ values presented here mainly reflect agreement in phasing, due to the simple sinusoidal shape assumed by the mean seasonal fit in Equation 1, which is dominated by the first harmonic component at most stations. This is especially true in the Northern Hemisphere, where R $>0.9$ reflects perfect phase agreement and $0.75<\mathrm{R}<0.9$ reflects a 1 month lag between model and observations. In the Southern tropics, the meaning of $\mathrm{R}$ is less easily interpreted, due to the dual maxima in the seasonal cycles. In general, $\mathrm{R}>0.8$ indicates optimal phase agreement, while $\mathrm{R}<0.6$ indicates a 1 to 2 month lag. Shape also contributes more substantially to $\mathrm{R}$ in the Southern extratropics, even though the cycles there have a single seasonal maximum. $\mathrm{R}$ is generally $>0.85$ for perfect phase agreement, but may be as small as 0.45 to 0.65 for just a 1 month lag between model and observations in cases where the observed cycle is flatter than the model cycle (e.g., CGO in Figures 1 and 2). For the component tracers in Figure 3, $\mathrm{R}$ values of $<0$ always reflect a phase lag of at least 3 months or more, while $0<\mathrm{R}<0.6$ generally reflects a 2 month lag with observations.

\subsection{Latitudinal Gradient}

[33] The model latitudinal gradient relative to the South Pole generally agrees well with observations (Figure 4). A comparison of mean 1997-2004 model total $\mathrm{CO}_{2}$ vs. observations at 89 GLOBALVIEW stations yields a correlation of $\mathrm{R}=0.87$. The fossil fuel tracer dominates the gradient, causing most of the north-south difference, but the ocean tracer is important in creating a bulge at the equator, where $\mathrm{CO}_{2}$ outgases due to upwelling. The ocean tracer mixing ratio in northern hemisphere mid to high latitudes is lower than in the corresponding region in the southern hemisphere due to the natural southward net transport of inorganic carbon in the ocean. The "seasonal rectifier" effect, i.e., positive annual mean $\mathrm{CO}_{2}$ concentrations in the Northern Hemisphere, is evident in the land tracer. This well-documented effect results from trapping of terrestrial respiration fluxes near the surface during shallow winter 


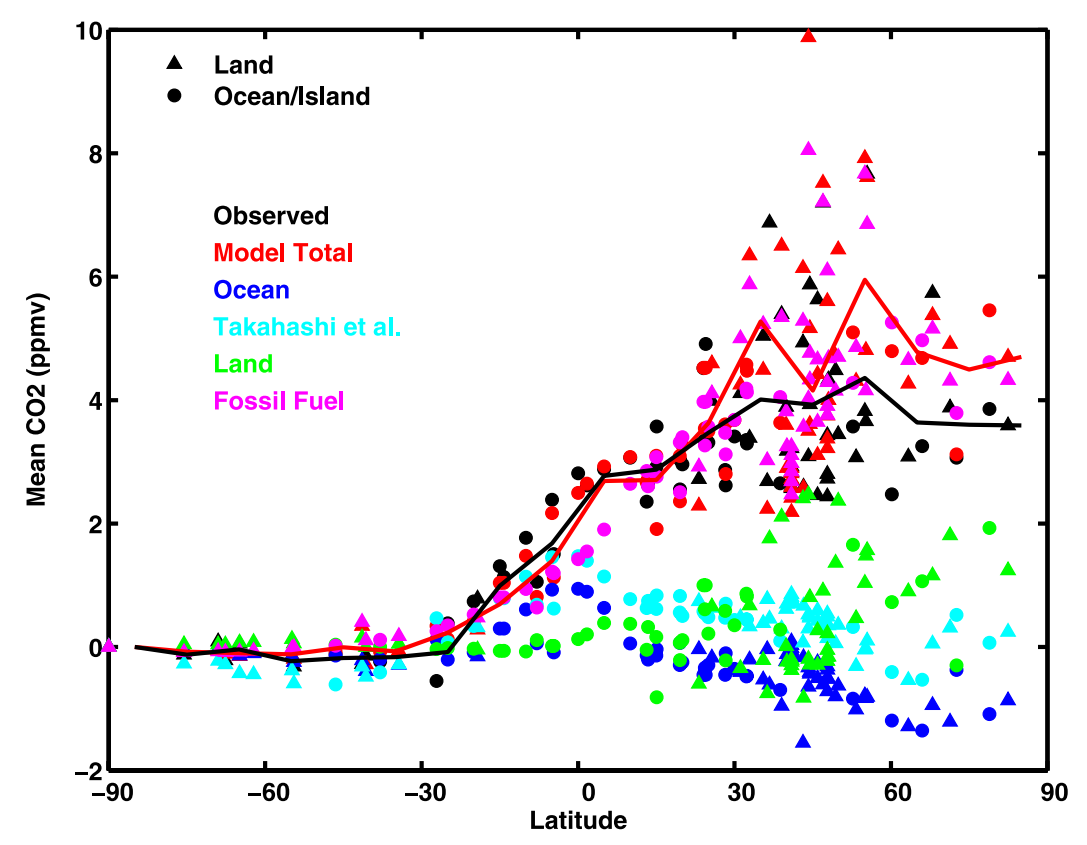

Figure 4. Mean value of total and component $\mathrm{CO}_{2}$ tracers at 89 GLOBALVIEW stations averaged from 1997 to 2004. The annual mean for each tracer in each individual year was normalized relative to its value at the South Pole (SPO) station. Triangles represent land-based stations. Circles are ocean stations. Black symbols are GLOBALVIEW data, blue symbols are WHOI best-case ocean, cyan symbols are Takahashi ocean, green symbols are GFED land, magenta symbols are fossil fuel, red symbols are model best-case total $\mathrm{CO}_{2}$ (defined in Table 1). The solid lines represent the average value per $10^{\circ}$ latitude bin for model total $\mathrm{CO}_{2}$ (red) and observations (black). The standard deviation of the bins (not shown) is $\sim \pm 2 \mathrm{ppm}$ for latitude bins $\geq 30^{\circ} \mathrm{N}$ and $< \pm 1 \mathrm{ppm}$ elsewhere.

planetary boundary layer conditions [Denning et al., 1995]. The north-south land gradient in Figure 4 appears only about half as strong as the cyclostationary MATCH:NCEP gradient presented by Gurney et al. [2003], possibly resulting from the inclusion of IAV in the current simulation, given the $\pm 2 \mathrm{ppm}$ interannual standard deviation of the model results north of $30^{\circ} \mathrm{N}$.

[34] The successful prediction of the observed latitudinal gradient, in addition to the generally good simulation of observed seasonal cycles described above, helps establish the model as a credible tool for investigating IAV. It also tends to contradict the hypothesis of overly strong interhemispheric transport of the northern land signal, although we cannot rule out that the good apparent agreement between model and observations may result from a cancellation of errors, e.g., between land and ocean tracers.

\subsection{Interannual Variability}

[35] Overall, the MATCH model is less able to simulate interannual than seasonal variability in atmospheric $\mathrm{CO}_{2}$. This result is illustrated below by showing atmospheric growth rate anomalies at 6 selected GLOBALVIEW stations (Figure 5) and by summarizing the model-observation comparisons in Taylor diagrams at all 89 stations for 1997-2004 simulations of land and total $\mathrm{CO}_{2}$ and at 33 stations for 1979-2004 simulations of ocean and fossil $\mathrm{CO}_{2}$ (Figure 6). Figure 5 shows that the land tracer dominates IAV in total $\mathrm{CO}_{2}$ at the 3 selected northern hemisphere stations (STM, LMP, MLO) and strongly influences the 3 southern hemisphere stations (PSA, CGO,
SMO). The ocean tracer also contributes to the amplitude of IAV in total $\mathrm{CO}_{2}$ at the southern stations, especially PSA and CGO. The fossil fuel tracer accounts for only a small fraction of the amplitude of IAV in total $\mathrm{CO}_{2}$ at all stations, with its largest contribution occurring at SMO.

[36] The Taylor diagram evaluation of best-case model total $\mathrm{CO}_{2}$ (Figure 6a) shows some success in reproducing the shape and phasing of observed IAV $(\mathrm{R} \sim 0.4$ to 0.8$)$. Of the 89 stations considered, the correlations are statistically significant at 11 stations at the $5 \%$ confidence level and an additional 9 are marginally significant at the $10 \%$ confidence level (Table 2). All of the statistically significant stations are in the northern hemisphere. Taylor diagrams of the model component $\mathrm{CO}_{2}$ tracers show that the highest correlation coefficients (R) between observed and model IAV are associated with the biomass burning component of the GFED land tracer. Biomass burning causes a large positive growth anomaly during the 1997-1998 El Niño that is matched in the observations at most stations. However, few of the apparent correlations between the biomass burning tracer and observations are statistically significant, according to our t-table analysis (Figure 2). The low significance is due to the high autocorrelation in the biomass burning time series, which are dominated by one primary maximum associated with the 1997-1998 El Niño and otherwise display relatively smooth behavior.

[37] Interestingly, the correlation coefficients between observations and the net ecosystem production (NEP) tracer tend to be more statistically significant, although only at northern hemisphere stations, even though the $\mathrm{R}$ values are 

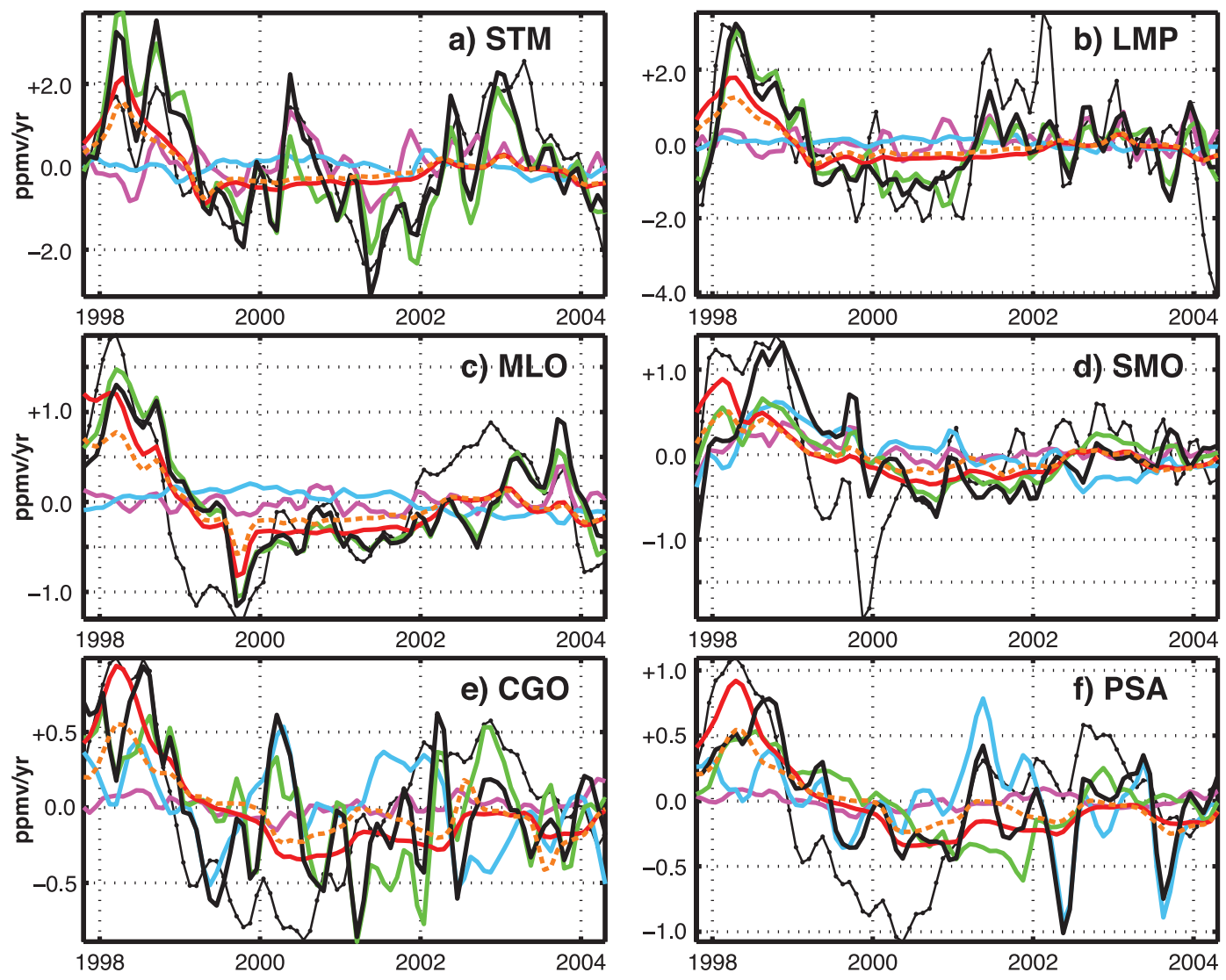

Figure 5. Atmospheric $\mathrm{CO}_{2}$ growth rate anomalies at six selected stations calculated by deseasonalizing and smoothing each time series, calculating the slope and removing the mean (see section 2.4.2 for details). Thin black line with symbols is GLOBALVIEW observations, blue line is WHOI best-case ocean, green line is total GFED land, red solid line is the best-case (CO-corrected) biomass burning component of GFED, red dotted line is the uncorrected biomass burning component of GFED, magenta line is fossil fuel. Solid heavy black line is model best-case total $\mathrm{CO}_{2}$. (a) Ocean Station, Norway, (b) Lampedusa, Italy, (c) Mauna Loa, Hawaii, (d) Samoa, (e) Cape Grim, Tasmania, and (f) Palmer Station, Antarctica. The correlation between model total $\mathrm{CO}_{2}$ and observations is significant at STM and LMP at the $5 \%$ level or better, according to a t-test.

generally lower than for biomass burning (Table 2 and Figures $6 \mathrm{c}$ and $6 \mathrm{~d}$ ). NEP is a noisier tracer than BB and thus has lower autocorrelation and reproduces more than one feature of observed IAV at the statistically significant stations (Figures 5a and 5b). The total GFED land term (BB + NEP) matches observed IAV better than either individual term alone, with statistically significant correlation coefficients at 16 out of 89 stations, although only 3 of these are at the $5 \%$ confidence level or better (Table 2 and Figure $6 \mathrm{~b}$ ).

[38] The model captures the amplitude of observed variability relatively well at most stations in the extratropical northern hemisphere, but tends to underestimate the amplitude, typically by $\sim 30 \%$, in all other regions (Figure 6a). Still, the current model captures a larger fraction of the observed amplitude of IAV than the simulations of Dargaville et al. [2002], which underestimated the amplitude of observed IAV by $60 \%$ or more, even at high latitude northern stations. IAV in transport, ocean fluxes and improved estimates of biomass burning all likely contribute to the increased amplitude of IAV simulated by the current model.

[39] The original biomass burning fluxes from the forward GFED model show a weaker pulse in 1997-1998 than the a posteriori fluxes shown in Figure 5, which were corrected based on a $\mathrm{CO}$ inversion (see description in section 2.2.4). The corrected biomass burning tracer agrees better with observations, particularly at the tropical and southern hemisphere stations. The corrected and uncorrected BB tracers have similar correlation coefficients with observations, but, whereas the corrected tracer captures $\sim 40-80 \%$ of the observed amplitude in IAV, the uncorrected tracer can account for only $50 \%$ or less (see additional Taylor diagrams in auxiliary material, Figure S1). ${ }^{1}$

[40] Figure 6e suggests that ocean fluxes (from the WHOI model) may account for at least $\sim 10 \%$ of the amplitude of observed IAV and up to $50 \%$ at extratropical southern latitudes. However, the shape and phasing of variability is largely uncorrelated to observations in either the northern or southern hemisphere, indicating that the ocean is not the primary driver of the observed atmospheric variations. Similarly, the fossil fuel tracer is generally uncorrelated to observed IAV (Figure 6f), and accounts for 30\% or less of

${ }^{1}$ Auxiliary materials are available in the HTML. doi:10.1029/ 2007JG000408. 

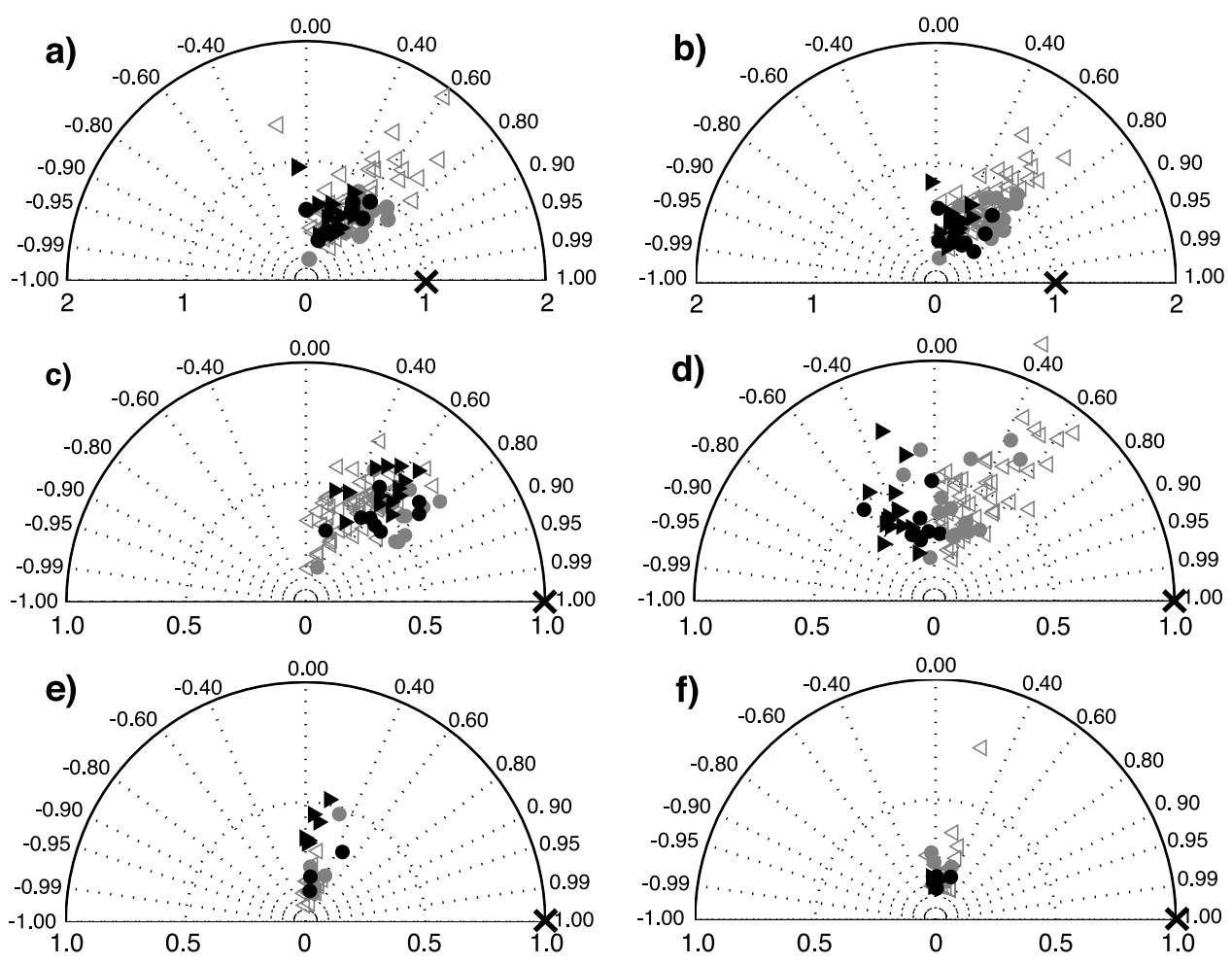

Figure 6. Taylor diagrams comparing IAV in model total and component $\mathrm{CO}_{2}$ tracer growth rate to GLOBALVIEW observations. Symbols are as described in Figure 2. (a) Best-case total $\mathrm{CO}_{2}$, (b) GFED land, (c) best-case biomass burning (BB) component of GFED, (d) Net ecosystem production (NEP) component of GFED, (e) WHOI best-case ocean, and (f) fossil fuel. Figures 6a-6d include 89 stations from 1997 to 2004 (Table 2). Figures 6e and 6f include 33 stations from 1979 to 2004 (Table 3).

the amplitude of IAV, with its largest contributions occurring in the northern hemisphere. For the typical degrees of freedom $(\nu \sim 30$, after accounting for autocorrelation) involved in the 1979-2004 analysis of fossil and ocean tracers, amplitude ratios (as inferred from $\sigma_{\text {model }} / \sigma_{\text {obs }}$ ratios) of $<0.7$ reflect statistically significant differences between model and observations. Thus, even though the correlation coefficients between observations and fossil or ocean tracers are statistically significant at a handful of stations, according to our t-table test (Table 3 ), the small $\sigma_{\text {model }} / \sigma_{\text {obs }}$ ratios at those stations (Figures 6e and 6f) suggest that fossil and ocean tracers can only partially account for the observed IAV.

\subsection{RMS Variability}

[41] Figures 7 and 8 present an additional perspective by showing the spatial patterns of root mean squared (RMS) variability in the model $\mathrm{CO}_{2}$ tracers. In Figure 7 , the seasonal variability in carbon dioxide is $\sim 4$ times larger than the IAV (note different color bar scales in Figures 7a and $7 \mathrm{~b}$ ). Land fluxes dominate the contribution to both seasonal and interannual RMS variability in the northern hemisphere and the tropics. Even in the extratropical southern hemisphere, the land flux of $\mathrm{CO}_{2}$ contributes a 0.4 to 0.7 portion of the seasonal variability and a larger portion, 0.5 to 1 , of the IAV. The ocean carbon tracer contributes 0.1 or less of total RMS variability over northern land and 0.3 or less over northern ocean for both seasonal and interannual RMS variability. Over the Southern Ocean, the ocean tracer portion is comparable in importance to land for seasonal and interannual RMS variability. In contrast, the land tracer, whose signal is mainly transported from the northern hemisphere according to sensitivity tests, tends to dominate variability over the Antarctic continent.

[42] The fossil fuel portion of seasonal RMS variability is 0.1 or less in most regions, except near the equator. Fossil fuel contributes more substantially to interannual RMS variability in both hemispheres with portional values ranging up to 0.7 to 1 in tropical regions. The relatively large contribution of fossil fuel to seasonal and interannual RMS variability near the equator appears to be related to shifts in the ITCZ operating on the strong north-south fossil $\mathrm{CO}_{2}$ gradient.

[43] For both land and ocean $\mathrm{CO}_{2}$, the combination of IAV in both surface fluxes and atmospheric transport leads to more interannual RMS variability than for cyclostationary fluxes with IAV in transport alone (Figure 8). For ocean tracers, the best-case WHOI ocean flux tracer has $\sim 1.5-$ 3 times more RMS variability than the cyclostationary flux tracer in most regions (Figures $8 \mathrm{a}-8 \mathrm{c}$ ). For land tracers, RMS variability is $1-5$ times as high for the best-case GFED land flux vs. the cyclostationary land flux with IAV in atmospheric transport (Figures $8 \mathrm{e}-8 \mathrm{~g}$ ). The ratios of cyclostationary to best-case RMS variability help identify areas where transport causes most of the IAV, regardless of the source variability. For ocean tracers, Figure 8c shows that transport variability is very important in the North Atlantic/Arctic Ocean, where surface fluxes are small due 
a) Total RMS Seasonal

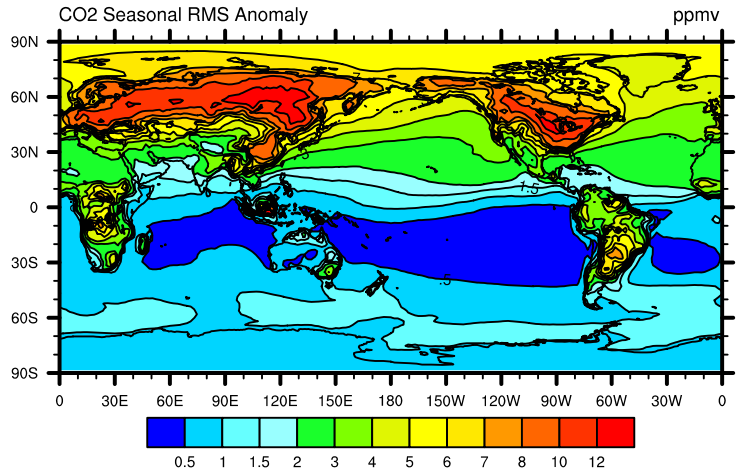

c) Ocean Portion Seasonal

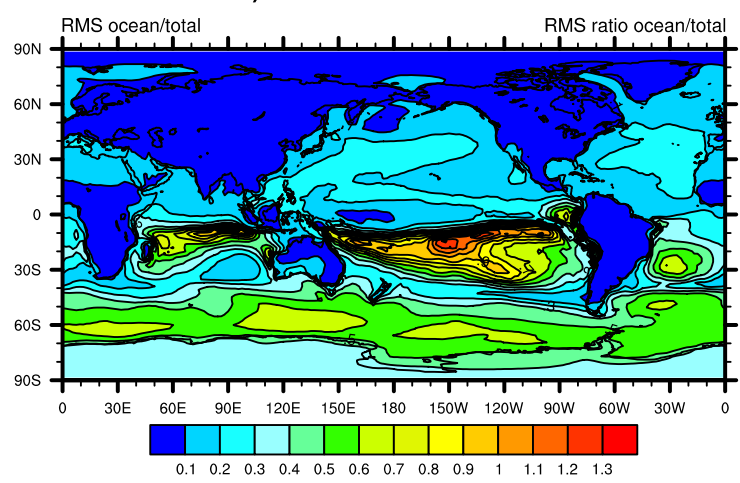

e) Land Portion Seasonal

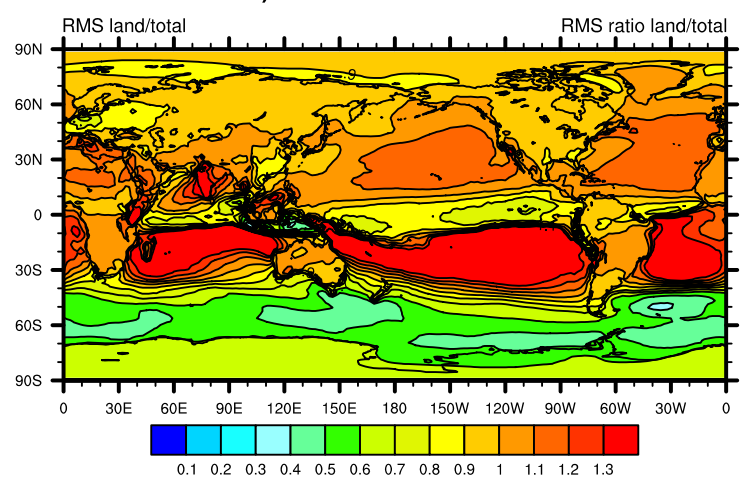

g) FF Portion Seasonal

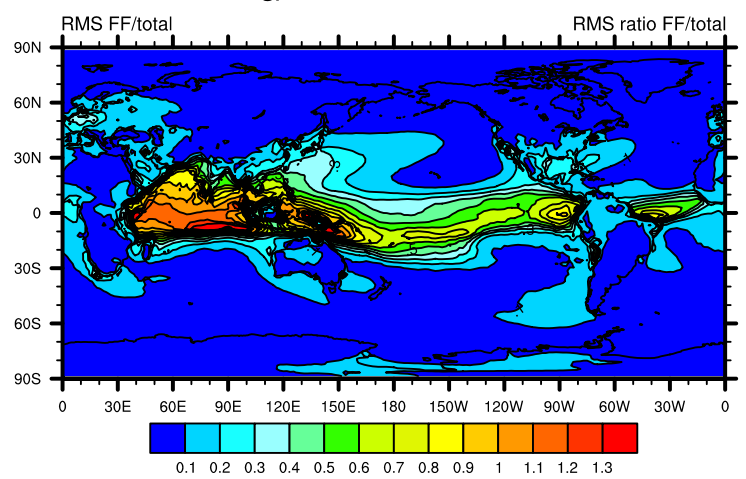

b) Total RMS Interannual

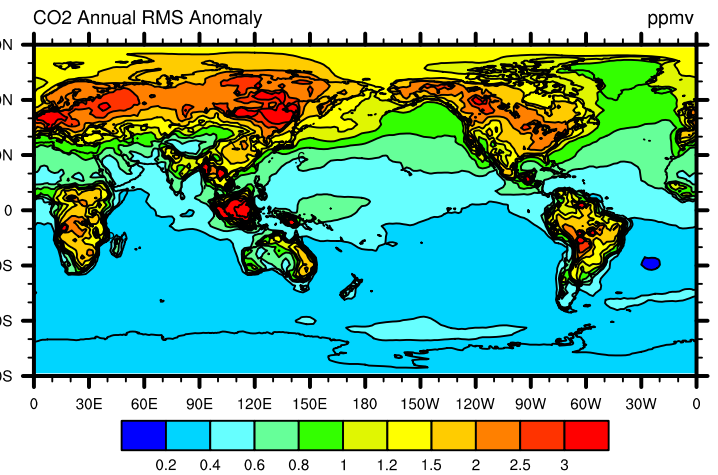

d) Ocean Portion Interannual

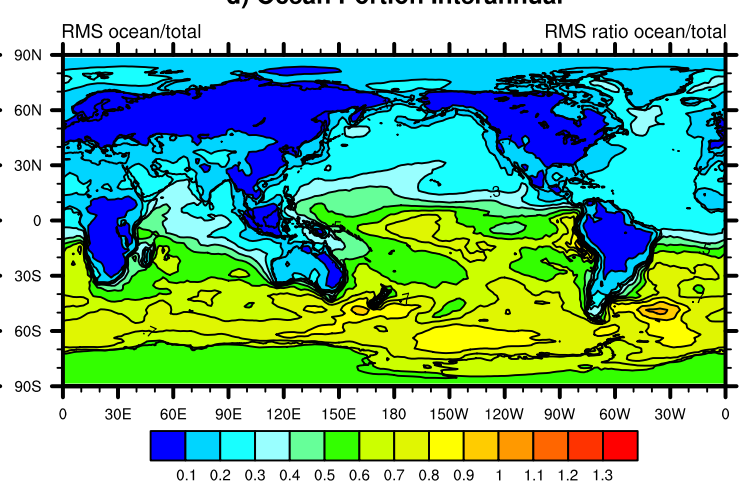

f) Land Portion Interannual

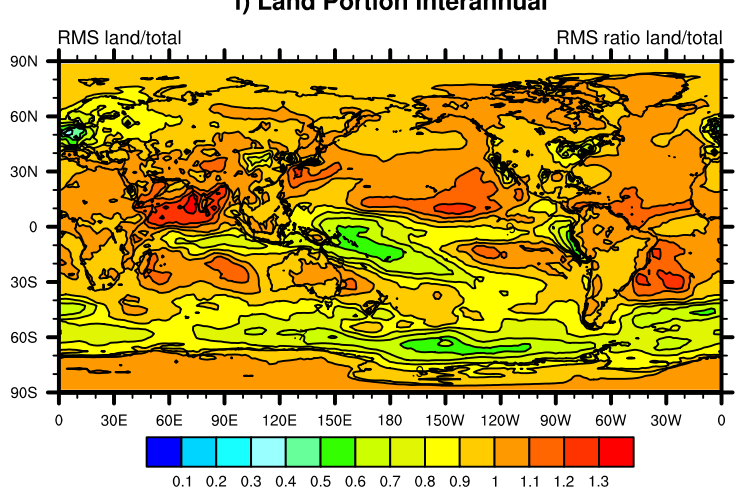

h) FF Portion Interannual

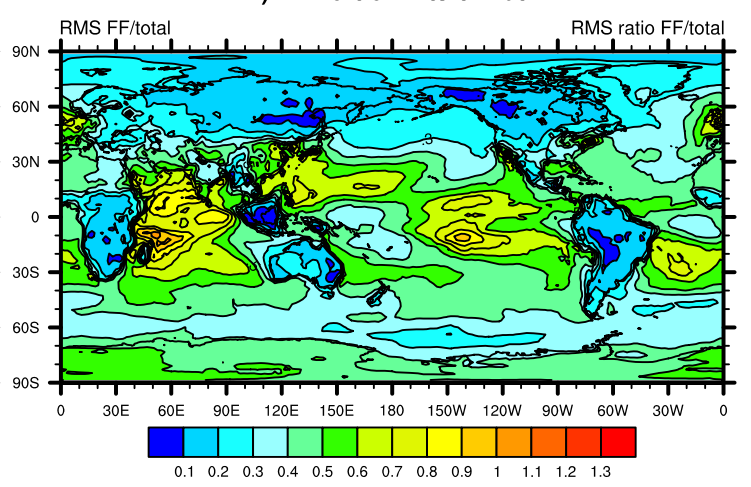

Figure 7. Absolute RMS variability (in ppmv) from 1997 to 2004 of best-case total $\mathrm{CO}_{2}$. (a) Seasonal, (b) interannual (note different color bar scale). Portional contribution to RMS seasonal variability: (c) best-case WHOI ocean, (e) GFED land, (g) fossil fuel. Portional contribution to RMS interannual variability (d) best-case WHOI ocean, (f) GFED land, (h) fossil fuel. Note that portional RMS variabilities of ocean, land, and fossil fuel add up to $>1$ when cancellation among component tracers occurs in the summing of total $\mathrm{CO}_{2}$ (see section 2.4.4 for more details). 
a) RMS 1997-2004 Cyclostationary Ocean

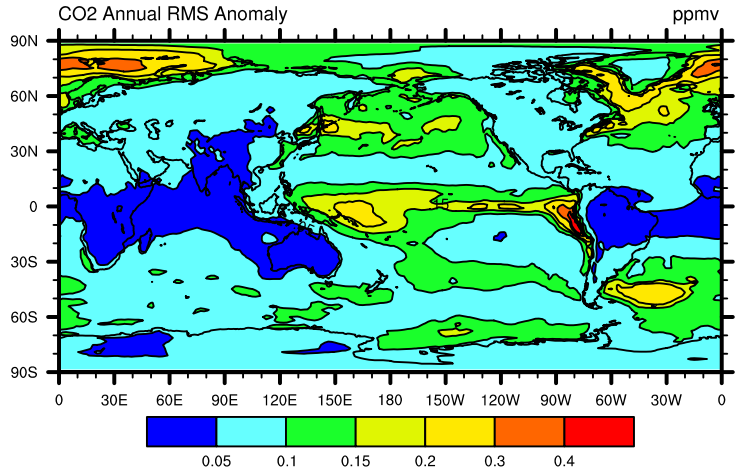

c) RMS 1997-2004 Ratio Cyclostat./Best Ocean

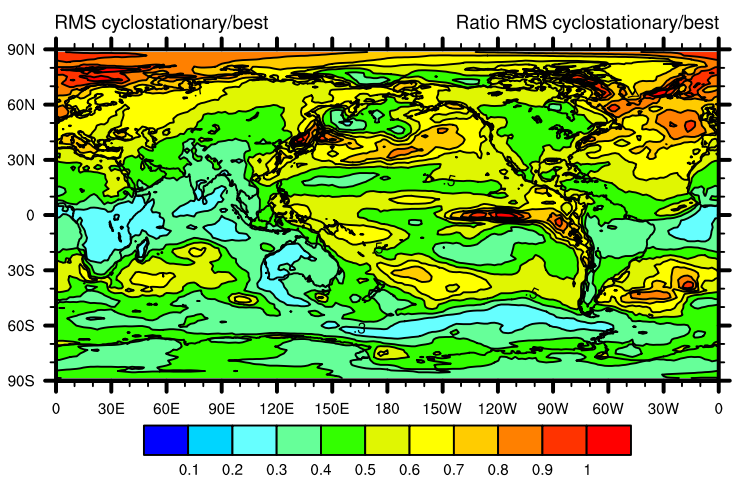

e) RMS 1997-2004 Cyclostationary Land

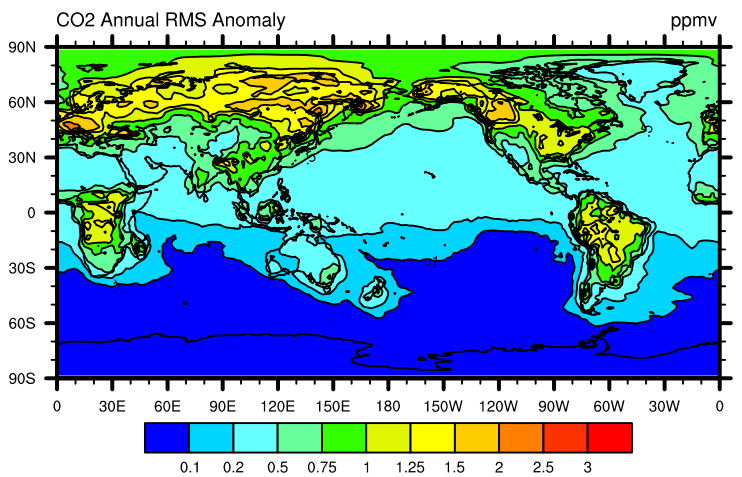

g) RMS 1997-2004 Ratio Cyclostat./GFED Land

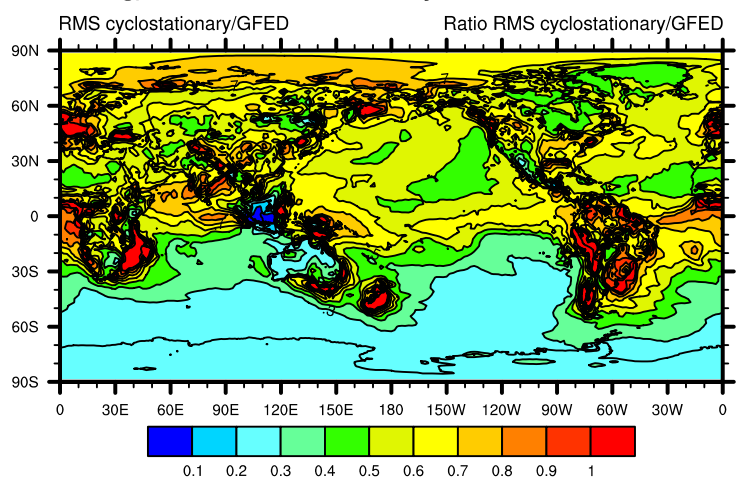

b) RMS 1997-2004 Best Ocean

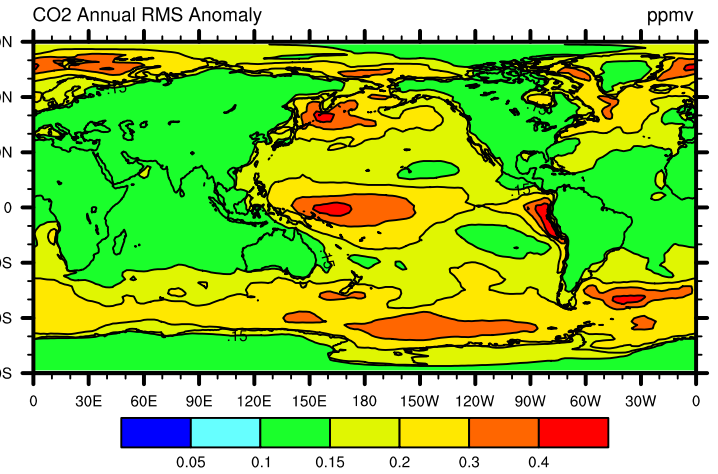

d) RMS 1997-2004 Best Ocean Surface Flux

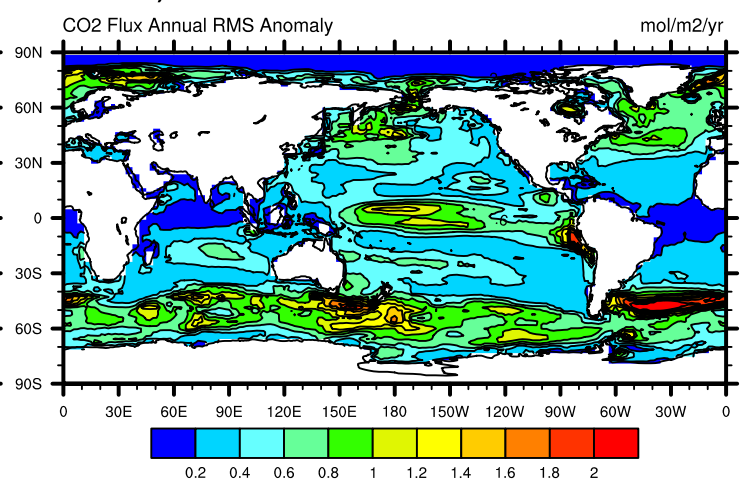

f) RMS 1997-2004 Best (GFED) Land

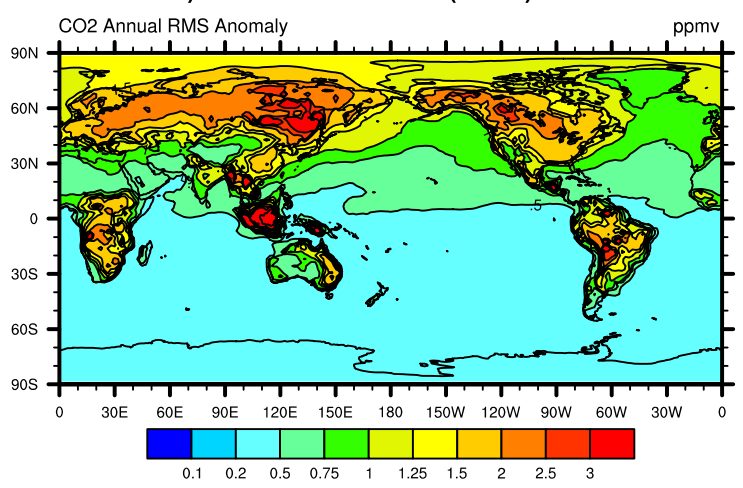

h) RMS 1997-2004 Best Land Surface Flux

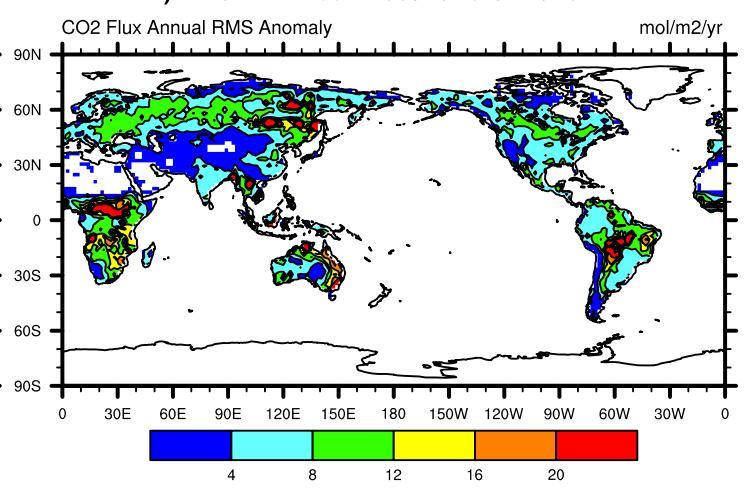

Figure 8. RMS interannual variability from 1997 to 2004, (a) cyclostationary WHOI ocean (ppmv), (b) best-case WHOI ocean (ppmv), (c) ratio of Figure 8a over Figure 8b, (d) best-case WHOI surface flux $\left(\mathrm{mol} / \mathrm{m}^{2} / \mathrm{yr}\right.$ ), (e) cyclostationary neutral biosphere land (ppmv), (f) GFED land (ppmv), (g) ratio of Figure 8e over Figure $8 f$, and (h) best-case GFED surface flux (mol $/ \mathrm{m}^{2} / \mathrm{yr}$ ). 


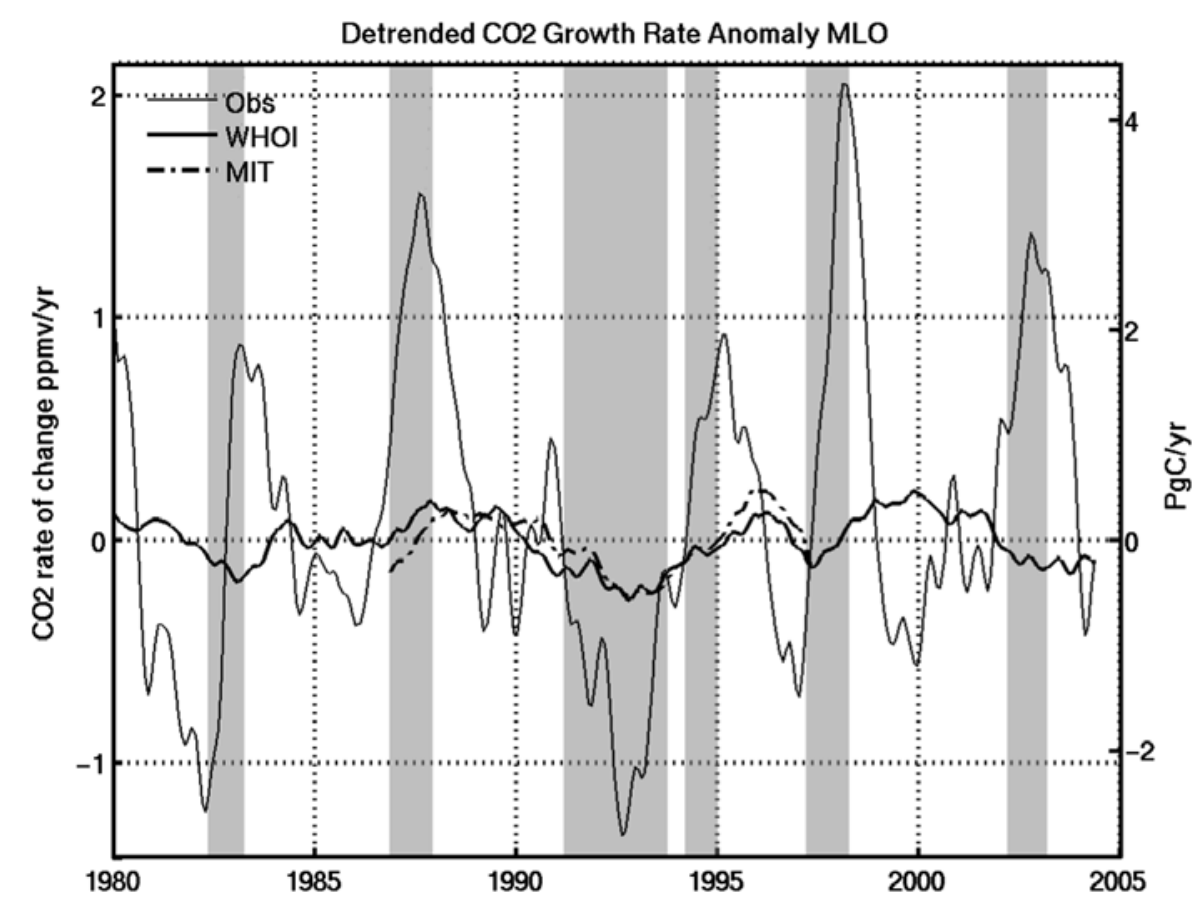

Figure 9. IAV at Mauna Loa of observed $\mathrm{CO}_{2}$ (thin solid line), best-case WHOI ocean tracer (heavy solid line), and MIT ocean tracer (dot-dashed line). Shaded bars represent warm ENSO periods defined based on a sustained Southern Oscillation Index (Tahiti - Darwin sea level pressure difference anomaly) of $<-1$ and usually coinciding, except during the weak sustained El Niño of the early 1990s, with a sea surface temperature anomaly in the tropical central to eastern Pacific of $>1{ }^{\circ} \mathrm{C}$ (http://www.cpc.noa.gov/ data/indices/sstoi.indices).

to sea ice coverage and the ratio of cyclostationary/best-case RMS is $\sim 1$. For land tracers, Figure $8 \mathrm{~g}$ shows there are few coherent areas where transport variability is dominant.

\section{Oceanic Contribution to IAV}

\subsection{ENSO Events}

[44] Figure 9 looks specifically at the link between the El Niño/Southern Oscillation (ENSO) and the contribution of ocean fluxes to IAV in the atmospheric $\mathrm{CO}_{2}$ growth anomaly. Results are shown from 1979-2004 at Mauna Loa station, which is often taken as representative of global atmospheric $\mathrm{CO}_{2}$ but which is also well situated to register changes over the tropical Pacific, where ENSO events are centered. Figure 9 shows decreases in the WHOI ocean $\mathrm{CO}_{2}$ tracer during the 1982-1983, early 1990s, 1997-1998 and 2002 ENSO events. No obvious decrease occurs during the 1987-1988 ENSO event. The largest of the ENSO-related decreases in the ocean $\mathrm{CO}_{2}$ growth anomaly occurs during the early 1990s, which experienced relatively weak but unusually long and sustained El Niño conditions. Similar results are seen in 1986-1997 simulations using $\mathrm{CO}_{2}$ fluxes from the MIT ocean model. The mechanism behind the decrease in the ocean $\mathrm{CO}_{2}$ tracer during El Niño conditions is well understood. The equatorial ocean, especially the eastern tropical Pacific, is normally one of the major regions of oceanic $\mathrm{CO}_{2}$ outgassing. Under El Niño conditions, outgassing is decreased by a thickening of the thermocline in the eastern tropical Pacific and a reduction in the upwelling of $\mathrm{CO}_{2}$-enriched deepwater [Feely et al., 1999]. Slackening of tradewinds during El Niño events can also contribute to reduced air-sea transfer of $\mathrm{CO}_{2}[$ McKinley et al., 2004a].

[45] In contrast to the model ocean tracers, the observed $\mathrm{CO}_{2}$ growth rate at Mauna Loa increases strongly after most of the ENSO events, especially in 1997-1998. The observations in Figure 9 are supported by a large body of literature, in which positive growth rate anomalies in atmospheric $\mathrm{CO}_{2}$ are well known to occur during warm ENSO conditions [Bacastow, 1976; Dettinger and Ghil, 1998; Rayner et al., 1999; Prentice et al., 2001; Baker et al., 2006]. These positive growth anomalies must be caused by increased $\mathrm{CO}_{2}$ outgassing from land, since ocean $\mathrm{CO}_{2}$ fluxes decrease during El Niño events, as discussed above. Warm ENSO conditions produce drought conditions over tropical land, particularly over Southeast Asia, which can lead to increased net $\mathrm{CO}_{2}$ efflux due to a reduction in $\mathrm{CO}_{2}$ uptake by photosynthesis [Hirano et al., 2007] or an increase in $\mathrm{CO}_{2}$ release by fire and/or heterotrophic respiration. Evidence involving complementary atmospheric carbon monoxide (CO) data suggests that enhanced $\mathrm{CO}_{2}$ release associated with drought-induced fire may cause $\sim 2 / 3$ of the positive $\mathrm{CO}_{2}$ growth anomaly [Van der Werf et al., 2004; Randerson et al., 2005]. The model results presented earlier (Figures 5 and 6), in which some of the strongest correlations between observed and model IAV were driven by the biomass burning component of the land tracer, tend to support this conclusion. The lack of available GFED land $\mathrm{CO}_{2}$ fluxes prior to 1997 precludes a more long-term evaluation of the terrestrial model tracer response during earlier ENSO events. 

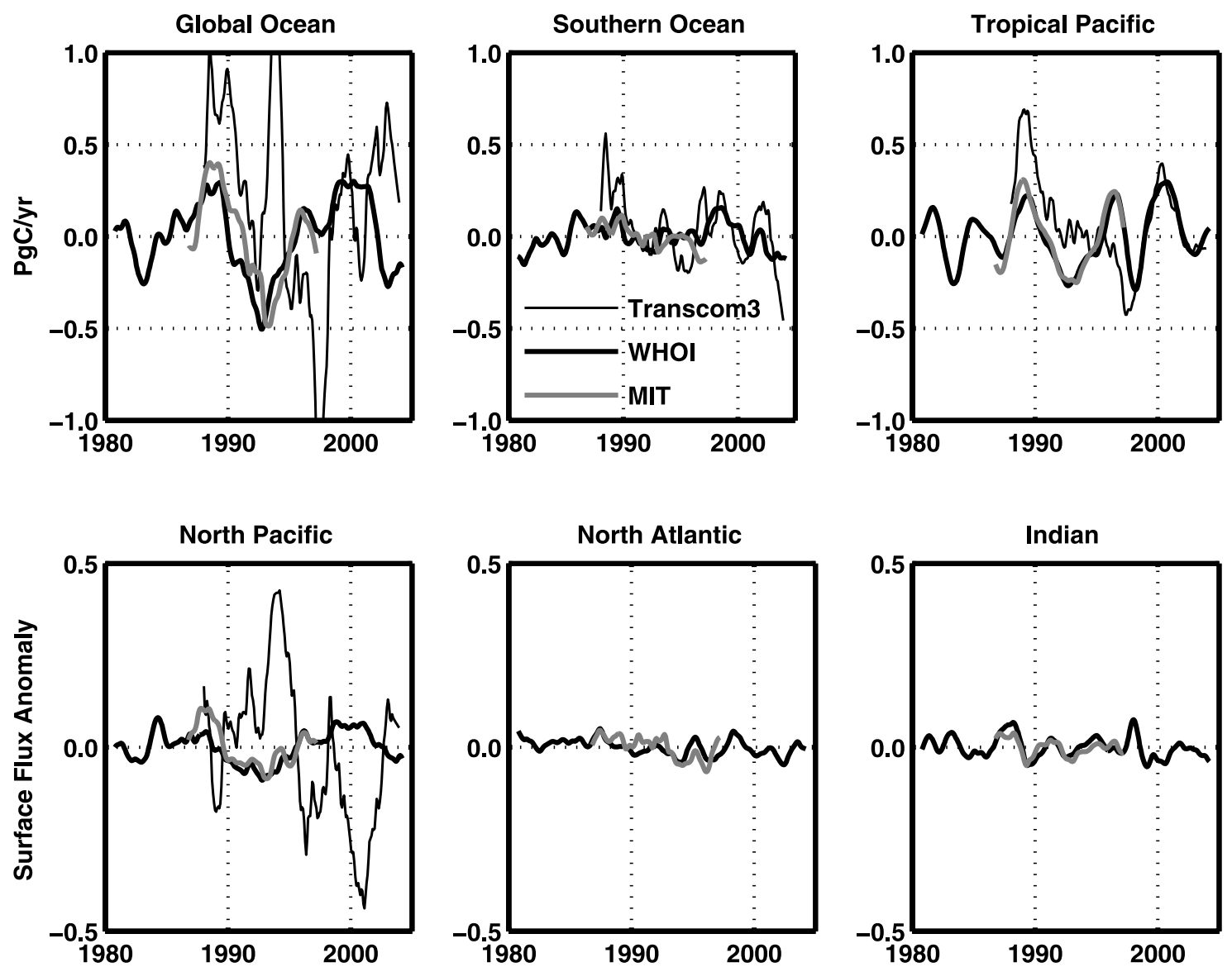

Figure 10. Interannual variability in integrated surface fluxes, calculated as deviations from the mean after deseasonalizing the ocean model results with a 12-month running average with three successive triangular smoothings. The heavy black line is the best-case WHOI ocean model from 1979 to 2004, and the heavy gray line is the MIT ocean model from 1986 to 1997 . The thin black line is the IAV in ocean fluxes inferred by the Transcom3 atmospheric $\mathrm{CO}_{2}$ inversion [Baker et al., 2006]. Regions are defined based on aggregated Transcom 3 regions: (a) global ocean, (b) Southern Ocean (all sectors south of $45^{\circ} \mathrm{S}$ ), (c) Tropical Pacific ( $\pm 15^{\circ}$ around the equator), (d) North Pacific (north of $16^{\circ}$ ending at Arctic Ocean), (e) North Atlantic (north of $16^{\circ} \mathrm{N}$, including Arctic Ocean), and (f) Indian Ocean (all areas north of $45^{\circ} \mathrm{S}$ ). Note that the Transcom 3 fluxes in the North Atlantic and Indian Oceans are not considered robust [Baker et al., 2006] and therefore not shown.

[46] The tendency of the model ocean tracer to decrease during El Niño events suggests that an even stronger terrestrial drought/fire response may be needed during the events to counteract the ocean signal and explain the observed positive growth rate anomalies. Interestingly, the observed $\mathrm{CO}_{2}$ growth rate begins to decline well before the ocean $\mathrm{CO}_{2}$ tracer. In this respect, the WHOI model does not support the hypothesis that the ocean is responsible for decrease in the $\mathrm{CO}_{2}$ growth rate that is generally observed before the onset of an El Niño event [Rayner et al., 1999; Dargaville et al., 2002]. A similar result was found by McKinley et al. [2004a] using the MIT ocean model.

[47] A period of agreement in phasing between the observations and the WHOI and MIT ocean model tracers occurs during the early 1990s, when all 3 tracers show a decrease in the $\mathrm{CO}_{2}$ growth anomaly (Figure 9). The ENSO event of the early 1990 s is an exception to the more typical ENSO patterns and responses described above. The early 1990s was a weak but sustained El Niño period that coincided with the eruption of the Mount Pinatubo volcano (in June 1991). The eruption injected a large amount of sulphate aerosol into the stratosphere, resulting in increased deflection of solar radiation and global cooling for several years thereafter. Most previous studies have attributed the observed atmospheric $\mathrm{CO}_{2}$ decrease of the early 1990 s to a land biosphere response to the Pinatubo eruption [Roderick et al., 2001; Gu et al., 2003], although the exact mechanism is poorly understood [Prentice et al., 2001; Krakauer and Randerson, 2003; Baker et al., 2006]. The current study suggests that the ocean may have accounted for $20-25 \%$ of this decrease.

\subsection{Surface Ocean Fluxes}

[48] Examination of the integrated model surface ocean fluxes suggests that the tropical Pacific dominates IAV (Figure 10). McKinley et al. [2004a] reached a similar conclusion using the MIT model (which is also shown in Figure 10) and attributed most of the tropical Pacific variability to ENSO events. During these events, large 
changes in upwelling, winds and sea surface temperature converge over sustained and correlated spatiotemporal scales to make a discernible impact on atmospheric $\mathrm{CO}_{2}$. The standard deviation of the IAV in the integrated tropical Pacific $\mathrm{CO}_{2}$ flux is $\pm 0.15 \mathrm{PgC} / \mathrm{yr}$ from 1979 to 2004 for the WHOI model and $\pm 0.18 \mathrm{PgC} / \mathrm{yr}$ from 1986 to 1997 for the MIT model. The Southern Ocean makes the second most import contribution to global ocean IAV, with a standard deviation of $\pm 0.07 \mathrm{PgC} / \mathrm{yr}$ for both WHOI and MIT (Figure 10). Both models both predict small IAV in the North Pacific, North Atlantic and Indian Oceans $\mathrm{CO}_{2}$ fluxes with standard deviations of only \pm 0.02 to $0.05 \mathrm{PgC} / \mathrm{yr}$ for these regions.

[49] The similarity in IAV predicted by the WHOI and MIT ocean models is intriguing, particularly considering that these two ocean carbon models have quite different biogeochemical algorithms (a prognostic ecosystem model vs. a simple export production parameterization) and horizontal resolutions. The similarity in their IAV predictions may indicate that large-scale surface physical drivers, e.g., heat fluxes and winds are ultimately responsible for the flux IAV and that these features can be captured in models with relatively coarse horizontal resolutions and simple ecosystem parameterizations.

[50] In contrast to the small IAV in the integrated surface fluxes shown in Figure 10, the standard deviation of the atmospheric growth rate anomaly in the MATCH/WHOI $\mathrm{CO}_{2}$ ocean tracer from 1979-2004 averages $\pm 0.35 \mathrm{Pg} \mathrm{C} / \mathrm{yr}$ at the 33 individual GLOBALVIEW stations summarized in Figure 6e, with a minimum to maximum range of $\pm 1 \mathrm{Pg} \mathrm{C} /$ $\mathrm{yr}$, on average, for the stations and as high as $\pm 2.3 \mathrm{Pg} \mathrm{C} / \mathrm{yr}$ at some stations. (This calculation employs the simple conversion $1 \mathrm{ppmv} / \mathrm{yr}=2.12 \mathrm{PgC} / \mathrm{yr}$, assuming mixing through the full atmosphere.) In addition, the latitudelongitude plot of RMS variability in the WHOI surface fluxes (Figure 8d) suggests high variability in the North Atlantic, North Pacific and Southern Ocean. This variability must be spatially and temporally incoherent, since it tends to be smoothed out when integrated over broad regions, as in Figure 10. However, one can hypothesize that the local variability in surface ocean fluxes seen in Figure $8 \mathrm{~d}$ interacts with local variability in transport to create larger variability in atmospheric $\mathrm{CO}_{2}$ than one might predict based on the integrated surface flux results in Figure 10. This hypothesis is tested below.

[51] The comparison of regional and global ocean fluxes from the Transcom3 atmospheric $\mathrm{CO}_{2}$ inversion to the integrated WHOI and MIT surface fluxes presents some interesting contrasts (Figure 10). In all regions except for the tropical Pacific, the IAV in the Transcom3 fluxes exceeds that predicted by the ocean models by at least a factor of 2 and up to a factor of 4 . The Transcom 3 results represent the a posteriori surface carbon fluxes inferred from atmospheric $\mathrm{CO}_{2}$ observations at a large range of GLOBALVIEW stations after accounting for the effects of atmospheric transport (using a wide range of transport models) on a prescribed a priori surface flux, which is "corrected" during the atmospheric inversion. Transcom3 used forward simulations of the Takahashi et al. [1999] database, an earlier version of the surface ocean $\mathrm{CO}_{2}$ flux climatology used in the current study, to precorrect atmospheric $\mathrm{CO}_{2}$ data for ocean influences. Transcom3 then assumed a spatially uniform flux pattern within each of its 11 ocean regions as the a priori ocean flux. The Transcom3 tropical Pacific flux is generally similar to the ocean model surface fluxes, but Transcom 3 does not predict the decrease in the early 1990s. On the contrary, Transcom 3 predicts a large increase in the global ocean flux during this time. In other regions, i.e., the Southern Ocean, Transcom 3 and the WHOI model display some coherence, but agreement is poor for the North Pacific and Global Ocean. Transcom3 fluxes in the North Atlantic and Indian Oceans are not considered robust [Baker et al., 2006].

[52] The reasons for the disagreements between Transcom 3 and the two ocean models presented in Figure 10 may include the fact that Transcom 3 used cyclostationary transport (with different models choosing different years) in its basis functions or that Transcom3 a priori ocean flux uncertainties are large enough that the inversions may assign variability to ocean regions that actually is due to land regions [Baker et al., 2006]. An additional factor may be that inversions work backward from atmospheric data at individual monitoring stations. As discussed above, atmospheric data contain substantially more variability than regionally integrated surface fluxes, due to the interaction of transport with spatiotemporal variability in the surface fluxes, which itself tends to be smoothed out when averaged over broad ocean regions.

[53] To test this latter potential bias in atmospheric inversions, we performed a forward simulation with MATCH using a surface ocean flux in which the IAV calculated by the Transcom3 atmospheric $\mathrm{CO}_{2}$ inversion from 1988 to 2003 [Baker et al., 2006] was prescribed within each of the 11 Transcom3 ocean regions, with the spatial variability within each region distributed in a uniform flux pattern. At individual grid cells in the Southern Ocean and North Pacific, the RMS variability of this "Transcom" $\mathrm{CO}_{2}$ flux was only $0.3 \mathrm{~mol} \mathrm{~m}^{-2} \mathrm{yr}^{-1}$, i.e., generally a factor of 3-7 times smaller than the RMS variability of the WHOI fluxes (Figure 8d). However, the "Transcom"/MATCH and WHOI/MATCH atmospheric $\mathrm{CO}_{2}$ growth rate anomalies at individual monitoring stations within the Southern Ocean and North Pacific regions showed IAV of more or less comparable amplitude. This result suggests that surface fluxes whose IAV is small locally (i.e., at individual grid cells) but spatiotemporally correlated across the region can yield IAV in atmospheric $\mathrm{CO}_{2}$ growth anomalies of similar amplitude as fluxes whose IAV is locally large but spatiotemporally uncorrelated. In the former case, the IAV in surface fluxes is reinforced when the fluxes are integrated across the region, while in the latter case integration leads to cancellation of IAV in the surface fluxes. The implication of this result is that it may be inappropriate to extrapolate to overly broad ocean regions the surface flux variability that has been inferred from the IAV in atmospheric $\mathrm{CO}_{2}$ observed at individual monitoring sites.

[54] Rödenbeck et al. [2003] have approached this problem by using an inversion strategy that confines the influence of monitoring station data to the area close to the station. As a result, the $\mathrm{CO}_{2}$ fluxes for large regions of the ocean with no nearby monitoring station do not change substantially from their a priori values. When integrated globally, this results in a low ocean interannual variability, in substantially better agreement with ocean models than the 
Transcom3 approach [McKinley et al., 2004b]. This can be interpreted to confirm the small variability of the ocean models but alternatively may simply reflect the fact that data coverage over the ocean is sparse.

\section{Summary/Conclusions}

[55] We have presented forward transport model simulations of atmospheric $\mathrm{CO}_{2}$ based on interannually varying land and ocean fluxes that are transported by interannually varying winds. The model is reasonably skilled at reproducing the seasonal cycles of atmospheric $\mathrm{CO}_{2}$ observed at 89 GLOBALVIEW monitoring stations. Performance is better in the northern hemisphere, where the land tracer dominates the seasonal cycle, than in the southern hemisphere, where ocean fluxes contribute substantially to the seasonal cycle. The model has lower skill at reproducing observed IAV in atmospheric $\mathrm{CO}_{2}$, especially in the southern hemisphere. However, the model does capture the strong positive growth anomaly observed during the 1997-1998 ENSO event and supports the hypothesis that biomass burning fluxes drive much of this IAV, although longer time series with several major biomass burning events are needed to establish a statistically significant correlation between model and observed IAV. The model predicts that ocean $\mathrm{CO}_{2}$ fluxes contribute only a $<0.1$ to 0.3 portion to seasonal and interannual variability in atmospheric $\mathrm{CO}_{2}$ in the northern hemisphere, but may contribute as much as half of both seasonal and interannual variability in the extratropical southern hemisphere.

[56] In the future, we expect more modeling centers to predict carbon fluxes interactively inside coupled carbon cycle climate models [Friedlingstein et al., 2006]. The fact that the state-of-the-art models presented here are only partially able to capture the observed variability in $\mathrm{CO}_{2}$, especially on interannual timescales when forced with realistic meteorology and fire events, suggests that more work needs to be done in forward mode to improve terrestrial and ocean carbon process models and in inverse mode to assimilate $\mathrm{CO}_{2}, \mathrm{CO}_{2}$ flux and other biogeochemical data.

[57] The atmospheric growth rate of the ocean model $\mathrm{CO}_{2}$ tracer generally decreases during El Niño events. In contrast, the observed atmospheric $\mathrm{CO}_{2}$ growth anomaly is positive during most $\mathrm{El}$ Niño events, consistent with increased release of $\mathrm{CO}_{2}$ from net ecosystem production and/or biomass burning. An interesting exception occurs during the weak but sustained El Niño of the early 1990s, which coincides with the post-Pinatubo period. The ocean model tracer can account for $20-25 \%$ of the observed dip in the atmospheric $\mathrm{CO}_{2}$ growth rate during this time. This result is supported by a second ocean model (MIT) but not by the Transcom $3 \mathrm{CO}_{2}$ atmospheric inversion, which predicts a positive $\mathrm{CO}_{2}$ flux anomaly from the ocean during the early 1990s.

[58] The combination of IAV in both surface fluxes and transport typically yields two or more times as much variability than when the surface flux is cyclostationary. This is true for both land and ocean fluxes. The interaction of variable but spatiotemporally incoherent surface ocean fluxes with transport can help bring out larger variability in the atmosphere than is seen in surface fluxes themselves when the latter are integrated over broad regions. These factors can help explain some of the discrepancies between ocean models, which generally predict low variability in
$\mathrm{CO}_{2}$ fluxes, and atmospheric-based methods, which infer larger variability in ocean $\mathrm{CO}_{2}$ fluxes.

[59] Acknowledgments. We acknowledge the support of NASA grant NNG05GG30G and NSF grant ATM0628472. We also thank the many contributors to the GLOBALVIEW data product and the Transcom3 modeling effort. The MATCH simulations were conducted at the National Center for Atmospheric Research, a National Science Foundation funded facility.

\section{References}

Andres, R. J., G. Marland, I. Fung, and E. Matthews (1996), A $1^{\circ} \times 1^{\circ}$ distribution of carbon dioxide emissions from fossil fuel consumption and cement manufacture, 1950-1990, Global Biogeochem. Cycles, 10, 419-429.

Bacastow, R. B. (1976), Modulation of atmospheric carbon dioxide by the southern oscillation, Nature, 261, 116-118.

Baker, D. F., et al. (2006), TransCom 3 inversion intercomparison: Impact of transport model errors on the interannual variability of regional $\mathrm{CO}_{2}$ fluxes, 1988-2003, Global Biogeochem. Cycles, 20, GB1002, doi:10.1029/2004GB002439.

Battle, M., M. L. Bender, P. P. Tans, J. W. C. White, J. T. Ellis, T. Conway, and R. J. Francey (2000), Global carbon sinks and their variability inferred from atmospheric and $\delta^{13} \mathrm{C}$, Science, 287, 2467-2470.

Bender, M. L., D. T. Ho, M. B. Hendricks, R. Mika, M. O. Battle, P. P. Tans, T. J. Conway, B. Sturtevant, and N. Cassar (2005), Atmospheric $\mathrm{O}_{2} / \mathrm{N}_{2}$ changes, 1993-2002: Implications for the partitioning of fossil fuel $\mathrm{CO}_{2}$ sequestration, Global Biogeochem. Cycles, 19, GB4017, doi:10.1029/2004GB002410.

Bousquet, P., P. Peylin, P. Ciais, C. Le Quéré, P. Friedlingstein, and P. P. Tans (2000), Regional changes in carbon dioxide fluxes of land and oceans since 1980, Science, 290, 1342-1346.

Brenkert, A. L. (1998), Carbon dioxide emission estimates from fossil-fuel burning, hydraulic cement production, and gas flaring for 1995 on a one degree grid cell basis. (Available at http://cdiac.esd.ornl.gov/ndps/ ndp058a.html)

Carlin, B. P., and T. A. Louis (2000), Bayes and Empirical Bayes Methods for Data Analysis, Chapman and Hall, New York.

Crisp, D., et al. (2004), The Orbiting Carbon Observatory (OCO) Mission, Adv. Space Res., 34, 700-709.

Dargaville, R. J., R. M. Law, and F. Pribac (2000), Implications of interannual variability in atmospheric circulation on modeled $\mathrm{CO}_{2}$ concentrations and source estimates, Global Biogeochem. Cycles, 14, 931-943.

Dargaville, R. J., et al. (2002), Evaluation of terrestrial carbon cycle model through simulations of the seasonal cycle of $\mathrm{CO}_{2}$ : Results from transient simulations consisting of increasing $\mathrm{CO}_{2}$, climate, and land-use effects, Global Biogeochem. Cycles, 16(4), 1092, doi:10.1029/2001GB001426.

Dargaville, R. J., S. C. Doney, and I. Y. Fung (2003), Interannual variability in the interhemispheric atmospheric $\mathrm{CO}_{2}$ gradient: contributions from transport and the seasonal rectifier, Tellus, Ser. B, 55(2), 711-722.

Denning, A. S., I. Y. Fung, and D. A. Randall (1995), Latitudinal gradient of atmospheric $\mathrm{CO}_{2}$ due to seasonal exchange with land biota, Nature, $376,240-243$.

Dettinger, M. D., and M. Ghil (1998), Seasonal and interannual variations of atmospheric $\mathrm{CO}_{2}$ and climate, Tellus, Ser. B, 50(1), 1-24.

Doney, S. C., D. M. Glover, and R. G. Najjar (1996), A new coupled, onedimensional biological-physical model for the upper ocean: Applications to the JGOFS Bermuda Atlantic Time-series Study (BATS) site, Deep Sea Res., Part II, 43, 591-624.

Doney, S. C., W. G. Large, and F. O. Bryan (1998), Surface ocean fluxes and water-mass transformation rates in the coupled NCAR Climate System Model, J. Clim., 11, 1420-1441.

Doney, S. C., et al. (2004), Evaluating global ocean carbon models: The importance of realistic physics, Global Biogeochem. Cycles, 18, GB3017, doi:10.1029/2003GB002150.

Doney, S. C., S. Yeager, G. Danabasoglu, W. G. Large, and J. C. McWilliams (2007), Mechanisms governing interannual variability of upper ocean temperature in a global hindcast simulation, J. Phys. Oceanorg., 37, $1918-1938$

Feely, R. A., R. Wanninkhof, T. Takahashi, and P. Tans (1999), Influence of El Niño on the equatorial Pacific contribution to atmospheric $\mathrm{CO}_{2}$ accumulation, Nature, 398(6728), 597-601.

Feely, R. A., et al. (2002), Seasonal and interannual variability of $\mathrm{CO}_{2}$ in the equatorial Pacific, Deep Sea Res., Part II, 49, 2443-2469.

Friedlingstein, P., et al. (2006), Climate-carbon cycle feedback analysis: Results from the C4MIP model intercomparison, J. Clim., 19(14), $3337-3353$. 
Fung, I., K. Prentice, E. Matthews, J. Lerner, and G. Russell (1983), Threedimensional tracer model study of atmospheric $\mathrm{CO}_{2}$ : Response to seasonal exchanges with the terrestrial biosphere, J. Geophys. Res., $88(\mathrm{C} 2)$, $1281-1294$.

Fung, I. Y., C. J. Tucker, and K. C. Prentice (1987), Application of advanced very high resolution reiometer vegetation index to study atmosphere-biosphere exchange of $\mathrm{CO}_{2}$, J. Geophys. Res., 92(D3), 29993015 .

Geels, C., S. C. Doney, R. Dargaville, J. Brandt, and J. H. Christensen (2004), Investigating the sources of synoptic variability in atmospheric $\mathrm{CO}_{2}$ measurements over the Northern Hemisphere continents: A regional model study, Tellus, Ser. B, 56, 35-50.

Giglio, L., G. R. van der Werf, J. T. Randerson, G. J. Collatz, and P. S Kasibhatla (2006), Global estimation of burned area using MODIS active fire observations, Atmos. Chem. Phys., 6, 957-974. (Available at http:// www.atmos-chem-phys.net/6/957/2006/)

GLOBALVIEW-CO ${ }_{2}$ (2006), Cooperative Atmospheric Data Integration Project - Carbon Dioxide [CD-ROM], Natl. Oceanic and Atmos. Admin., Boulder, Colo. (Also available via anonymous FTP to ftp.cmdl.noaa.gov, Path: $\mathrm{ccg} / \mathrm{co} 2 / \mathrm{GLOBALVIEW})$

Gloor, M., N. Gruber, J. Sarmiento, C. Sabine, R. A. Feeley, and C. Rödenbeck (2003), A first estimate of present and preindustrial air-sea $\mathrm{CO}_{2}$ flux patterns based on ocean interior carbon measurements and models, Geophys. Res. Lett., 30(1), 1010, doi:10.1029/2002GL015594.

Gu, L. H., D. D. Baldocchi, and S. C. Wofsy (2003), Response of a deciduous forest to the Mount Pinatubo eruption: Enhanced photosynthesis, Science, 299(5615), 2035-2038.

Gurney, K., R. Law, P. Rayner, and A. S. Denning (2000), TransCom 3 experimental protocol, Pap. 707, Dep. of Atmos. Sci., Colo. State Univ., Boulder.

Gurney, K. R., et al. (2003), Transcom $3 \mathrm{CO}_{2}$ inversion intercomparison: 1. Annual mean control results and sensitivity to transport and prior flux information, Tellus, Ser. B, 55, 555-579.

Gurney, K. R., et al. (2004), Transcom 3 inversion intercomparison: Model mean results for the estimation of seasonal carbon sources and sinks, Global Biogeochem. Cycles, 18, GB1010, doi:10.1029/2003GB002111.

Gurney, K. R., Y.-H. Chen, T. Maki, S. R. Kawa, A. Andrews, and Z. Zhu (2005), Sensitivity of atmospheric $\mathrm{CO}_{2}$ inversions to seasonal and interannual variations in fossil fuel emissions, J. Geophys. Res., 110, D10308, doi:10.1029/2004JD005373

Hirano, T., S. Hendrik, T. Harada, S. Limin, T. June, R. Hirata, and M. Osaki (2007), Carbon dioxide balance of a tropical peat swamp forest in Kalimantan, Indonesia, Global Change Biol., 13(2), 412.

Houghton, R. A. (2003), Revised estimates of the annual net flux of carbon to the atmosphere from changes in land use and land management 1850 2000, Tellus, Ser. B, 55(2), 378-390.

Kalnay, E., et al. (1996), The NMC/NCAR 40-year reanalysis project, Bull. Am. Meteorol. Soc., 77, 437-471.

Keeling, C. D. (1961), The concentration and isotopic abundances of carbon dioxide in rural and marine air, Geochim. Cosmochim. Acta, 24, $277-298$

Keeling, C. D., R. B. Bacastow, A. F. Carter, S. C. Piper, T. P. Whorf, M. Heimann, W. G. Mook, and H. Roeloffzen (1989), A three-dimensiona model of atmospheric $\mathrm{CO}_{2}$ transport based on observed winds: 1 . Analysis of observational data, in Aspects of Climate Variability in the Pacific and the Western Americas, Geophys. Monogr. Ser., vol. 55, edited by D. H. Person, pp. 165-236, AGU, Washington, D. C

Keeling, R. F., S. C. Piper, and M. Heimann (1996), Global and hemispheric $\mathrm{CO}_{2}$ sinks deduced from changes in atmospheric $\mathrm{O}_{2}$ concentration, Nature, 391, 218-221.

Krakauer, N. Y., and J. T. Randerson (2003), Do volcanic eruptions enhance or diminish net primary production? Evidence from tree rings, Global Biogeochem. Cycles, 17(4), 1118, doi:10.1029/2003GB002076.

Krakauer, N. Y., J. T. Randerson, F. W. Primeau, N. Gruber, and D. Menemenlis (2006), Carbon isotope evidence for the latitudinal distribution and wind speed dependence of the air-sea gas transfer velocity, Tellus, Ser. B, 58, 390-417.

Langenfelds, R. L., R. J. Francey, B. C. Pak, L. P. Steele, J. Lloyd, C. M. Trudinger, and C. E. Allison (2002), Interannual growth rate variations of atmospheric $\mathrm{CO}_{2}$ and its $\delta^{13} \mathrm{C}, \mathrm{H}_{2}, \mathrm{CH}_{4}$, and $\mathrm{CO}$ between 1992 and 1999 linked to biomass burning, Global Biogeochem. Cycles, 16(3), 1048 , doi:10.1029/2001GB001466.

Lee, K., R. Wanninkhof, T. Takahashi, S. C. Doney, and R. A. Feely (1998), Low interannual variability in recent oceanic uptake of atmospheric carbon dioxide, Nature, 396, 155-159.

Le Quéré, C., J. C. Orr, P. Monfray, and O. Aumont (2000), Interannual variability of the oceanic sink of $\mathrm{CO}_{2}$ from 1979 through 1997, Global Biogeochem. Cycles, 14, 1247-1265.

Le Quéré, C., et al. (2003), Two decades of ocean $\mathrm{CO}_{2}$ sink and variability, Tellus, Ser. B, 55, 649-656.
Mahowald, N. M., P. J. Rasch, B. E. Eaton, S. Whittlestone, and R. G. Prinn (1997), Transport of radon-222 to the remote troposphere using the Model of Atmospheric Transport and Chemistry and assimilated winds from ECMWF and the National Center for Environmental Prediction/ NCAR, J. Geophys. Res., 102, 28,139-28,151.

Marland, G., T. A. Boden, and R. J. Andres (2003), Global, regional, and national $\mathrm{CO}_{2}$ emissions, in Trends: A Compendium of Data on Global Change, pp. 505-584, Carbon Dioxide Inf. Anal. Cent., Oak Ridge Natl. Lab., U.S. Dep. of Energy, Oak Ridge, Tenn. (Available at http://cdiac. esd.ornl.gov/trends/emis/tre glob.htm)

Masarie, K. A., and P. P. Tans (1995), Extension and integration of atmospheric carbon dioxide data into a globally consistent measurement record, J. Geophys. Res., 100, 11,593-11,610.

Matsumoto, K., and N. Gruber (2005), How accurate is the estimation of anthropogenic carbon in the ocean? An evaluation of the $\Delta \mathrm{C}^{*}$ method Global Biogeochem. Cycles, 19, GB3014, doi:10.1029/2004GB002397.

McKinley, G. A., M. J. Follows, and J. Marshall (2004a), Mechanisms of air-sea $\mathrm{CO}_{2}$ flux variability in the equatorial Pacific and the North Atlantic, Global Biogeochem. Cycles, 18, GB2011, doi:10.1029/ 2003GB002179.

McKinley, G. A., C. Rödenbeck, M. Gloor, S. Houweling, and M. Heimann (2004b), Pacific dominance to global air-sea $\mathrm{CO}_{2}$ flux variablility: A novel atmospheric inversion agrees with ocean models, Geophys. Res. Lett., 31, L22308, doi:10.1029/2004GL021069.

McKinley, G. A., et al. (2006), North Pacific carbon cycle response to climate variability on seasonal to decadal timescales, J. Geophys. Res. 111, C07S06, doi:10.1029/2005JC003173.

Moore, J. K., S. C. Doney, J. C. Kleypas, D. M. Glover, and I. Y. Fung (2002), An intermediate complexity marine ecosystem model for the global domain, Deep Sea Res., Part II, 49, 403-462.

Moore, J. K., S. C. Doney, and K. Lindsay (2004), Upper ocean ecosystem dynamics and iron cycling in a global three-dimensional model, Global Biogeochem. Cycles, 18, GB4028, doi:10.1029/2004GB002220.

Obata, A., and Y. Kitamura (2003), Interannual variability of the sea-air exchange of $\mathrm{CO}_{2}$ from 1961 to 1998 simulated with a global ocean circulation-biogeochemistry model, J. Geophys. Res., 108(C11), 3337, doi:10.1029/2001JC001088

Olsen, S. C., and J. T. Randerson (2004), Differences between surface and column atmospheric $\mathrm{CO}_{2}$ and implications for carbon cycle research, J. Geophys. Res., 109, D02301, doi:10.1029/2003JD003968.

Orr, J. C., et al. (2001), Estimates of anthropogenic carbon uptake from four three-dimensional global ocean models, Global Biogeochem. Cycles, $15(1), 43-60$.

Prentice, I. C., G. D. Farquhar, M. J. R. Fasham, M. L. Goulden, M. Heimann, V. J. Jaramillo, H. S. Kheshgi, and C. Le Quéré (2001), The carbon cycle and atmospheric carbon dioxide, in Climate Change 2001: The Scientific Basis, Contribution of Working Group I to the Third Assessment Report of the Intergovernmental Panel on Climate Change, edited by J. T. Houghton et al., pp. 183-287, Cambridge Univ. Press, New York.

Quay, P., R. Sonnerup, T. Westby, J. Stutsman, and A. McNichol (2003), Changes in the ${ }^{13} \mathrm{C} /{ }^{12} \mathrm{C}$ of dissolved inorganic carbon in the ocean as a tracer of anthropogenic $\mathrm{CO}_{2}$ uptake, Global Biogeochem. Cycles, 17(1), 1004, doi:10.1029/2001GB001817.

Randerson, J. T., M. V. Thompson, T. J. Conway, I. Y. Fung, and C. B Field (1997), The contribution of terrestrial sources and sinks to trends in the seasonal cycle of atmospheric carbon dioxide, Global Biogeochem. Cycles, 11, 535-560.

Randerson, J. T., et al. (2002), Carbon isotope discrimination of arctic and boreal biomes inferred from remote atmospheric measurements and a biosphere-atmosphere model, Global Biogeochem. Cycles, 16(3), 1028, doi:10.1029/2001GB001435

Randerson, J. T., G. R. van der Werf, G. J. Collatz, L. Giglio, C. J. Still, P. Kasibhatla, J. B. Miller, J. W. C. White, R. S. DeFries, and E. S. Kasischke (2005), Fire emissions from $\mathrm{C}_{3}$ and $\mathrm{C}_{4}$ vegetation and their influence on interannual variability of atmospheric $\mathrm{CO}_{2}$ and $\delta^{13} \mathrm{CO}_{2}$, Global Biogeochem. Cycles, 19, GB2019, doi:10.1029/2004GB002366.

Rasch, P. J., N. M. Mahowald, and B. E. Eaton (1997), Representations of transport, convection, and the hydrologic cycle in chemical transport models: Implications for the modeling of short-lived and soluble species, J. Geophys. Res., 102(D23), 28,127-28,138.

Rayner, P. J., R. M. Law, and R. Dargaville (1999), The relationship between tropical $\mathrm{CO}_{2}$ fluxes and the El Niño-Southern Oscillation, Geophys. Res. Lett., 26(4), 493-496.

Rödenbeck, C., S. Houweling, M. Gloor, and M. Heimann (2003), CO flux history 1982-2001 inferred from atmospheric data using a global inversion of atmospheric transport, Atmos. Chem. Phys., 3, 1919-1964.

Roderick, M. L., et al. (2001), On the direct effect of clouds and atmospheric particles on the productivity and structure of vegetation, Oecologia, 129(1), 21-30. 
Sarmiento, J. L., and E. T. Sundquist (1992), Revised budget for the oceanic uptake of anthropogenic carbon dioxide, Nature, 356, 589-593.

Sokal, R. R., and F. J. Rohlf (1981), Biometry, 859 pp., W. H. Freeman, New York.

Takahashi, T., R. H. Wanninkhof, R. A. Feely, R. F. Weiss, D. W. Chipman, N. Bates, J. Olafsson, C. Sabine, and S. C. Sutherland (1999), Net sea-air $\mathrm{CO}_{2}$ flux over the global oceans: An improved estimate based on the seaair $\mathrm{pCO}_{2}$ difference, in Proceedings of the 2nd International Symposium: $\mathrm{CO}_{2}$ in the Oceans, the 12th Global Environmental Tsukuba, 18-22 January 1999, edited by Y. Nojiri, Natl. Inst. for Environ. Stud., Environ. Agency of Jpn., Tokyo.

Takahashi, T., et al. (2002), Global sea-air flux based on climatological surface ocean $\mathrm{pCO}_{2}$, and seasonal biological and temperature effects, Deep Sea Res., Part II, 49, 1601-1622.

Taylor, K. E. (2001), Summarizing multiple aspects of model performance in a single diagram, J. Geophys. Res., 106(D7), 7183-7192.

Thoning, K. W., P. P. Tans, and W. D. Komhyr (1989), Atmospheric carbon dioxide at Mauna Loa Observatory: 2. Analysis of the NOAA GMCC data, 1974-1985, J. Geophys. Res., 94, 8549-8565.

Van der Werf, G. R., J. T. Randerson, G. J. Collatz, L. Giglio, P. S. Kasibhatla, A. F. Arellano, S. C. Olsen, and E. S. Kasischke (2004), Continental-scale partitioning of fire emissions during the 1997 to 2001 El Niño/La Niña period, Science, 303(5654), 73-76.

Van der Werf, G. R., J. T. Randerson, L. Giglio, G. J. Collatz, P. S Kasibhatla, and A. F. Arellano Jr. (2006), Interannual variability in global biomass burning emissions from 1997 to 2004, Atmos. Chem. Phys., 6, 3423-3441.

Wanninkhof, R. (1992), Relationship between wind speed and gas exchange over the ocean, J. Geophys. Res., 97(C5), 7373-7382.

Wanninkhof, R., and W. R. McGillis (1999), A cubic relationship between air-sea $\mathrm{CO}_{2}$ exchange and wind speed, Geophys. Res. Lett., 26(13), $1889-1892$

D. F. Baker, S. C. Doney, and I. D. Lima, Department of Marine Chemistry and Geochemistry, Woods Hole Oceanographic Institution, Woods Hole, MA 02543, USA.

P. Kasibhatla, Nicolas School of the Environment, Duke University, Durham, NC 27708, USA.

N. M. Mahowald, Department of Earth and Atmospheric Sciences, Cornell University, Ithaca, NY 14853, USA.

G. A. McKinley, Department of Atmospheric and Oceanic Sciences, University of Wisconsin, Madison, WI 53706, USA.

C. D. Nevison, National Center for Atmospheric Research, Boulder, CO 80307-3000, USA. (nevison@ucar.edu)

J. T. Randerson, Earth System Science Department, University of California, Irvine, CA 92697, USA.

G. R. van der Werf, Faculty of Earth and Life Sciences, Vrije Universiteit, 1081 HV Amsterdam, Netherlands. 